\title{
Designing Multifunctional 5-cyanoisophthalate Based Coordination Polymers as Single-Molecule Magnets, Adsorbents, and Luminescent Materials
}

\author{
Jose M. Seco, ${ }^{a}$ Itziar Oyarzabal, ${ }^{a}$ Sonia Pérez-Yáñez, ${ }^{b}$ Javier Cepeda, ${ }^{*},{ }^{a}$, Antonio \\ Rodríguez-Diéguez ${ }^{*}$ d
}

\begin{abstract}
${ }^{a}$ Departamento de Química Aplicada, Facultad de Química, Universidad del País Vasco/Euskal Herriko Unibertsitatea, UPV/EHU, 20018, San Sebastián, Spain. ${ }^{b}$ Departamento de Química Inorgánica, Facultad de Ciencia y Tecnología, Universidad del País Vasco/Euskal Herriko Unibertsitatea, UPV/EHU, Apartado 644, E-48080 Bilbao, Spain. ${ }^{c}$ Departamento de Ciencia y Tecnología de Polímeros, Facultad de Química, Universidad del País Vasco/Euskal Herriko Unibertsitatea, UPV/EHU, 20018, San Sebastian, Spain. 'Departamento de Química Inorgánica, Universidad de Granada, 18071, Granada, Spain.
\end{abstract}

S1. Additional structural data.

S2. Thermogravimetric analysis.

S3. Powder X-ray Diffraction Analysis.

S4. Dc susceptibility measurements.

S5. Ac susceptibility measurements.

S6. Spin density distributions.

S7. Adsorption measurements.

S8. Photoluminescence spectra.

S9. Photoluminescence lifetimes.

S10. TD-DFT computational results. 


\section{S1. Additional structural data.}

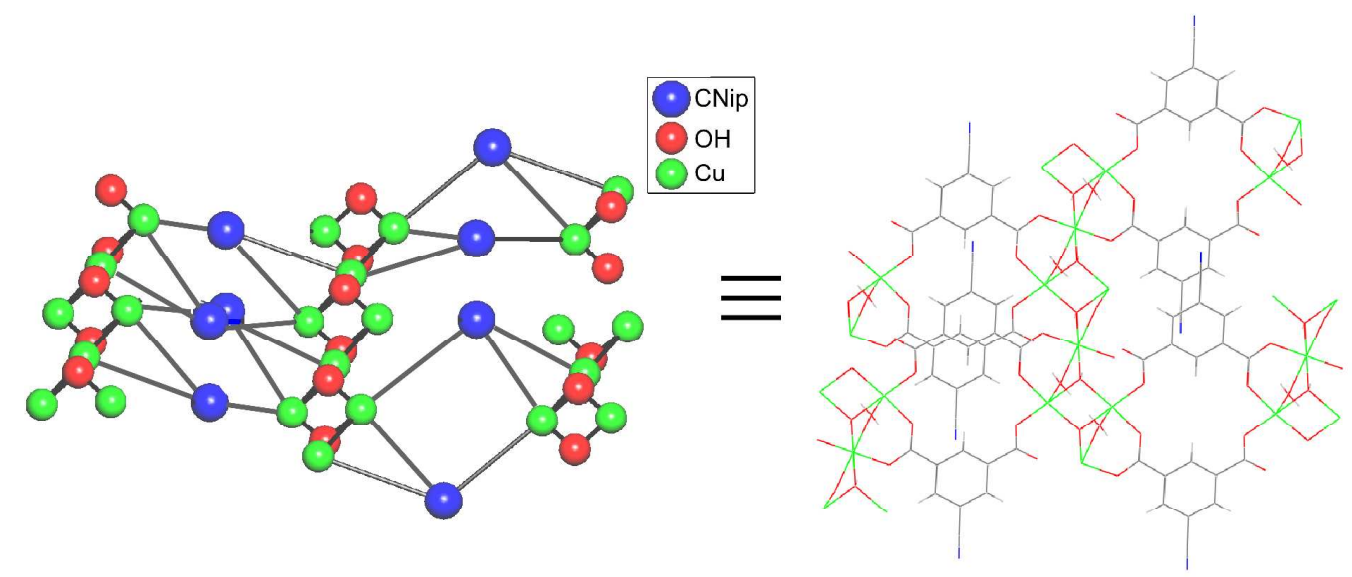

Figure S1. View of a fragment of a layer of compound 1 showing the topological network.
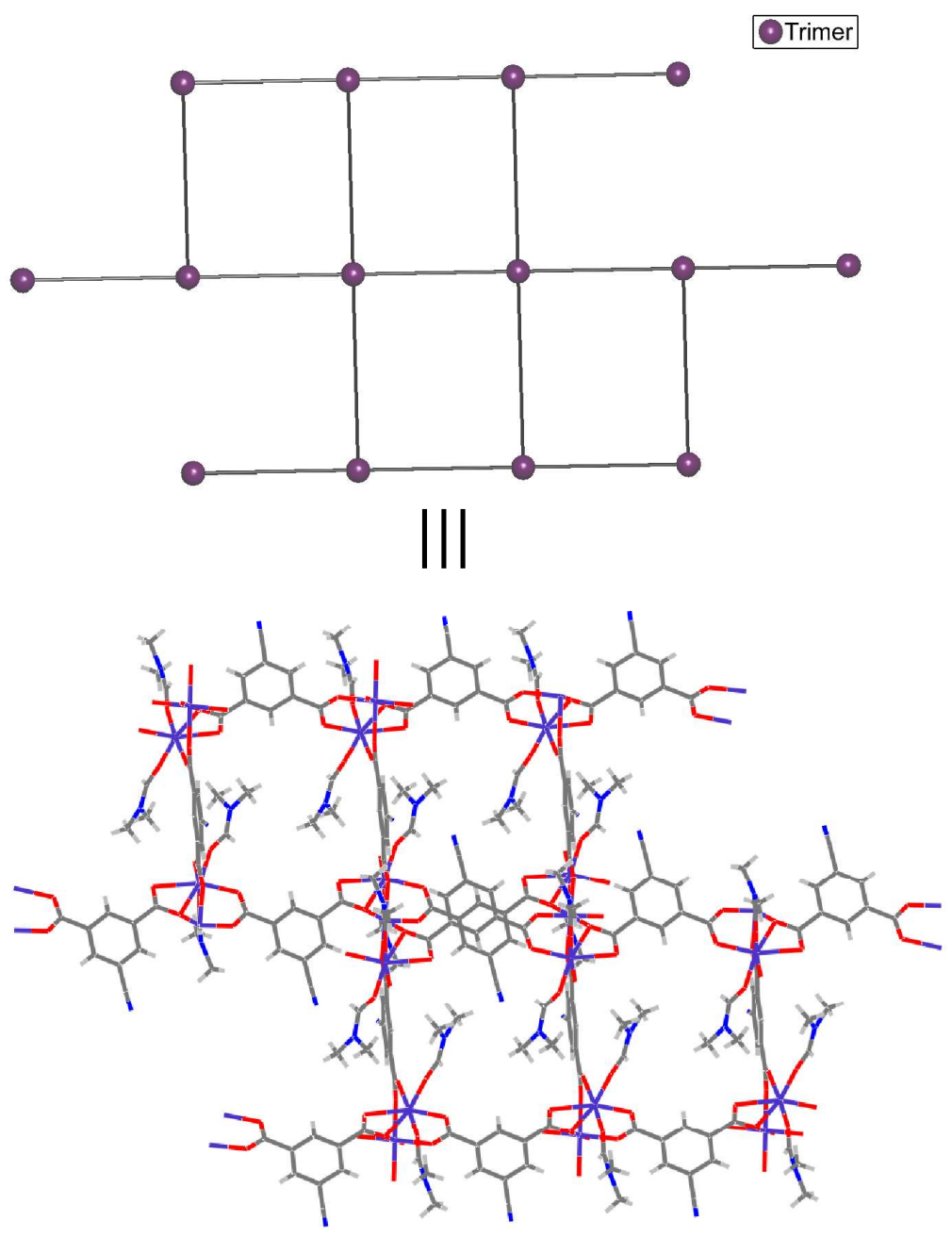

Figure S2. Topological network of compound 2. 


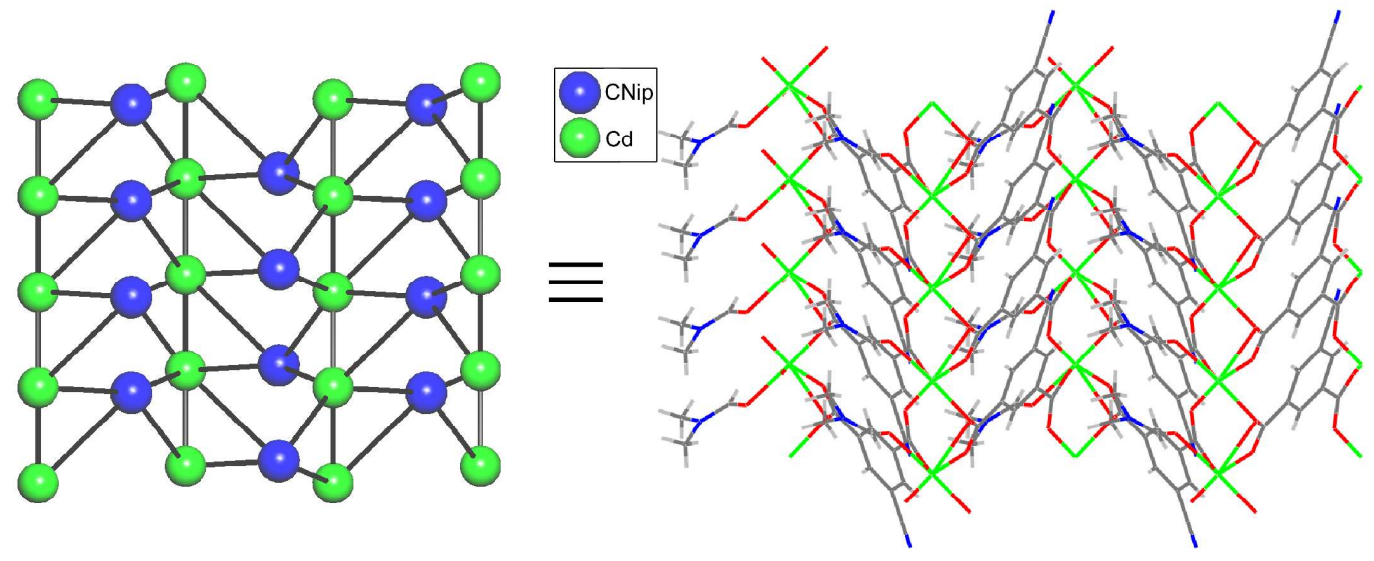

Figure S3. 3D packing of compound $\mathbf{3}$ showing the topological network.
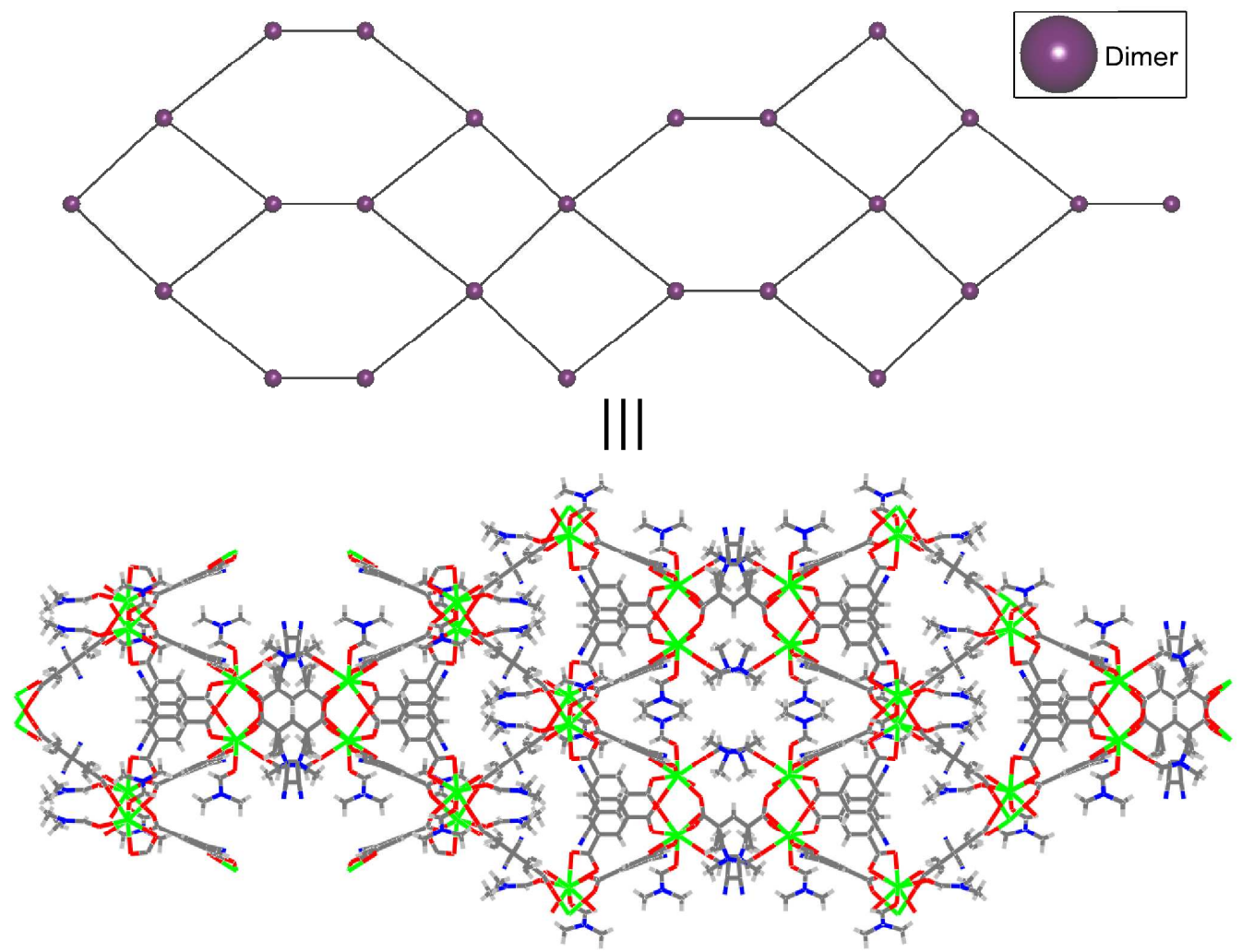

Figure S4. 3D packing of compound $\mathbf{4}$ showing the topological network grown upon the junction of dimers. 

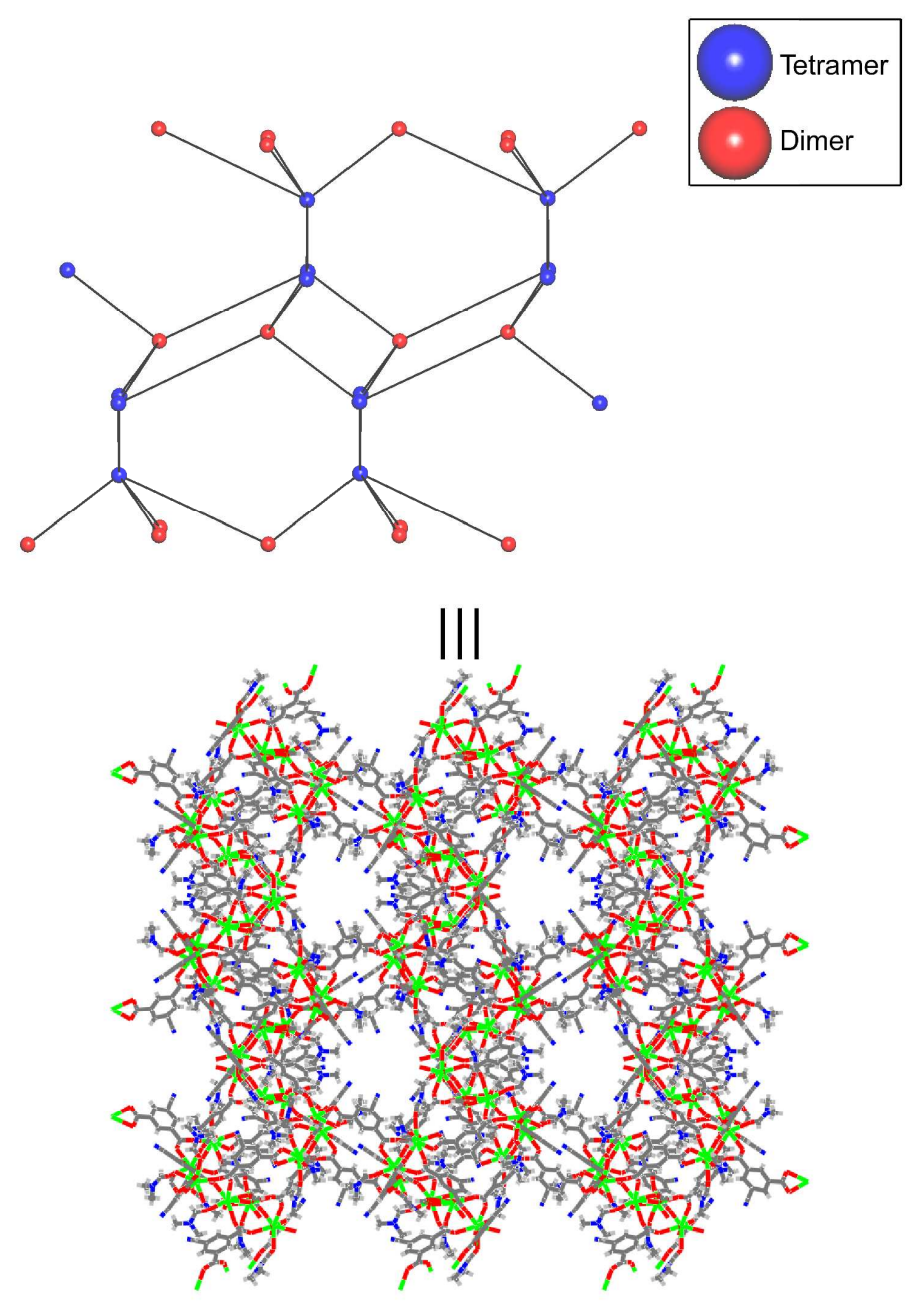

Figure S5. 3D packing of compound $\mathbf{5}$ showing the topological network grown upon the junction of 4-connected (dimers) and 6-connected (tetramers).

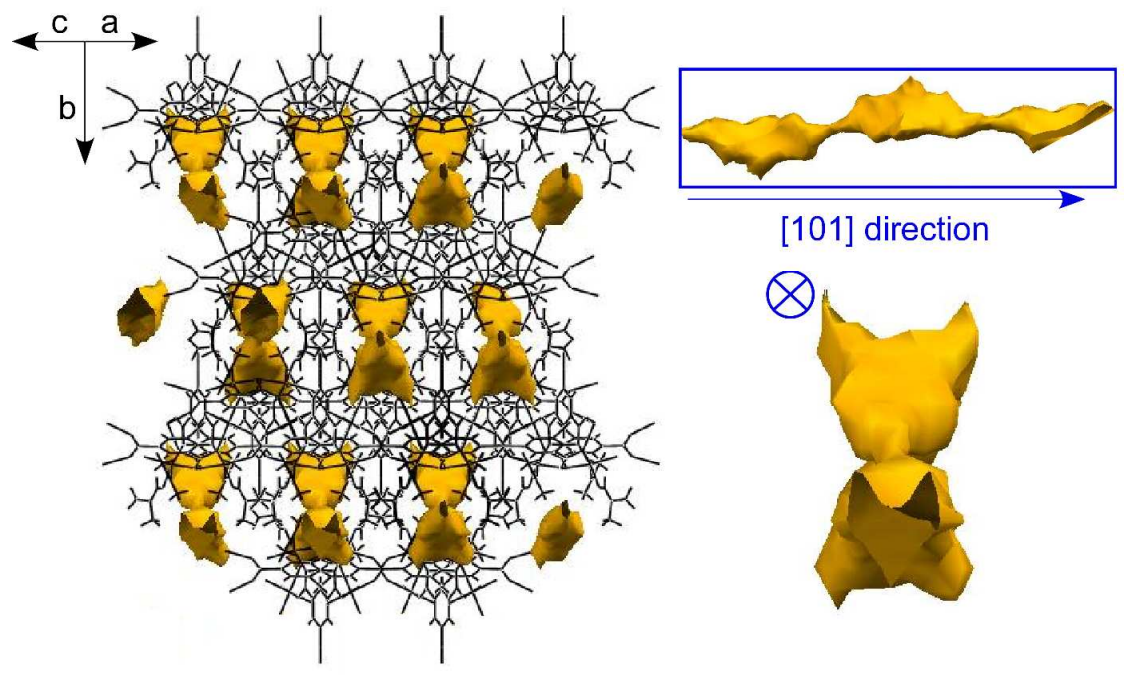

Figure S6. 3D crystal building of $\mathbf{2}$ showing the voids together with parallel and perpendicular views of the channels. 


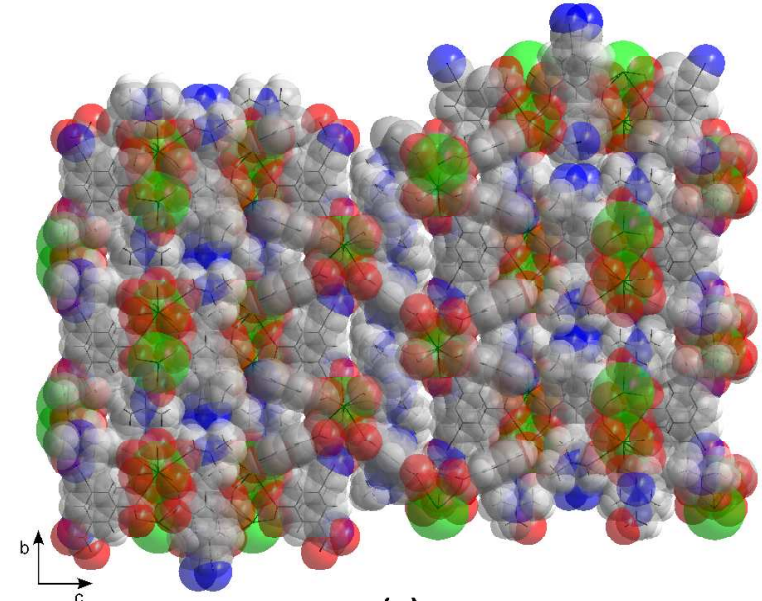

(a)

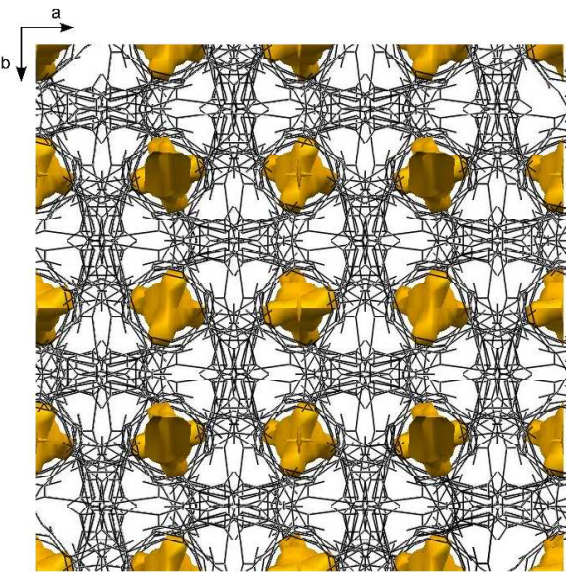

(b)

Figure S7. View of the packing of 4: (a) along $a$ axis; (b) showing the voids along $c$ axis.

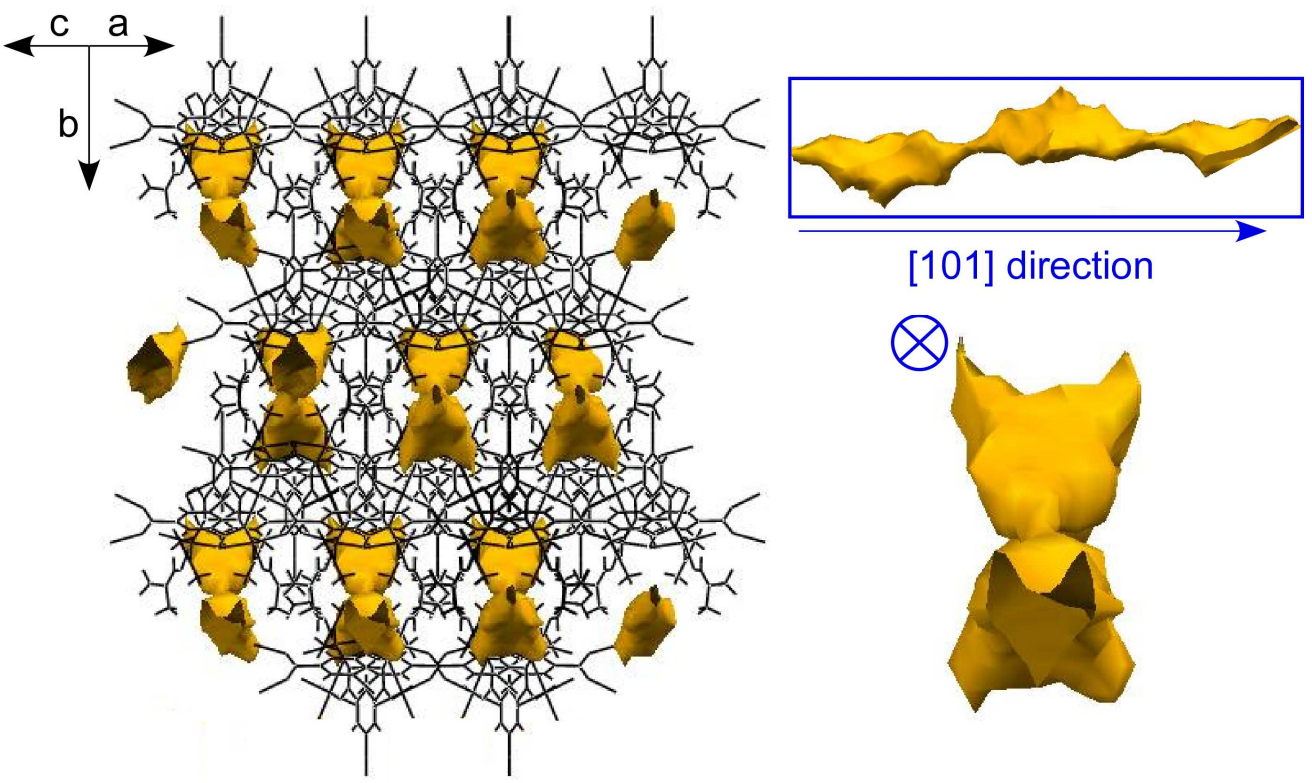

Figure S8. Coordination polyhedra of the gadolinium atoms in compound $\mathbf{5}$.

Table S1. Hydrogen bonding interactions $\left(\AA,^{\circ}\right)$ of compound 1. ${ }^{\mathrm{a}}$

\begin{tabular}{|c|c|c|c|c|}
\hline$D-H \cdots A^{b}$ & $D-H$ & $H \cdots A$ & $D \cdots A$ & $D-H \cdots A$ \\
\hline O1w-H11wN.N51A(iii) & 0.85 & 2.22 & $3.043(4)$ & 161.8 \\
\hline $\mathrm{O} 1 \mathrm{w}-\mathrm{H} 12 \mathrm{w} \cdots \mathrm{O} 32 \mathrm{~A}(\mathrm{iv})$ & 0.86 & 1.82 & $2.640(4)$ & 158.1 \\
\hline $\mathrm{O} 1-\mathrm{H} 1 \cdots \mathrm{N} 51 \mathrm{~A}(\mathrm{v})$ & 0.98 & 2.25 & $3.055(4)$ & 138.8 \\
\hline $\mathrm{O} 1-\mathrm{H} 1 \cdots \mathrm{O} 32 \mathrm{~A}(\mathrm{iv})$ & 0.98 & 2.29 & $2.907(3)$ & 120.1 \\
\hline
\end{tabular}

${ }^{a}$ Symmetry codes: (iii) $\mathrm{x}-1, \mathrm{y}, \mathrm{z}-1$; (iv) $\mathrm{x}+1, \mathrm{y}, \mathrm{z}$; (v) $\mathrm{x}, \mathrm{y}, \mathrm{z}-1 .{ }^{\mathrm{b}}$ D: donor. A: acceptor. 
Table S2. Structural parameters $\left(\AA,{ }^{\circ}\right)$ of $\pi-\pi$ interactions of compound $2 .^{\text {a }}$

\begin{tabular}{ccccccc}
\hline Ring $\cdots$ Ring $^{\mathrm{b}}$ & $\alpha$ & DC & $\beta$ & DZ & DXY & Dist. \\
\hline $1 \mathrm{~A}-1 \mathrm{~A}(\mathrm{ii})$ & 0.03 & $3.694(4)$ & 24.50 & 3.362 & 1.532 & $3.48-3.66$ \\
\hline
\end{tabular}

[a] Symmetry: (ii) $-\mathrm{x}-1,-\mathrm{y},-\mathrm{z}+1 . \alpha$ : dihedral angle between mean planes of the rings $\left(^{\circ}\right.$ ), DC: distance between ring centroids $(\AA), \beta$ : angle between DC vector and normal to plane $(\mathrm{I})\left(^{\circ}\right)$, DZ: perpendicular distance of the centroids of ring(I) on plane of ring(II) $(\AA)$, DXY: slippage $(\AA)$, Dist.: shorter distances between non-hydrogen atoms of rings (I) and (II). [b] Rings: 1A: C1A, C2A, C3A, C4A, C5A, C6A.

Table S3. Structural parameters $\left(\AA,{ }^{\circ}\right)$ of $\pi-\pi$ interactions of compound $6 .{ }^{\text {a }}$

\begin{tabular}{ccccccc}
\hline Ring $\cdots$ Ring $^{\mathrm{b}}$ & $\alpha$ & DC & $\beta$ & DZ & DXY & Dist. \\
\hline 1A-2A(ii) & 10.25 & $3.724(7)$ & 13.29 & 3.414 & - & $3.49-3.59$ \\
$2 \mathrm{~A}-1 \mathrm{~A}(\mathrm{i})$ & 10.25 & $3.725(7)$ & 23.54 & 3.625 & - & $3.49-3.59$ \\
$2 \mathrm{~A}-2 \mathrm{~A}(\mathrm{iii})$ & 0.00 & $3.788(7)$ & 23.59 & 3.471 & 1.516 & $3.76-3.80$ \\
\hline
\end{tabular}

[a] Symmetry: (i) $-\mathrm{y}+1 / 2, \mathrm{z},-\mathrm{x}+1 / 2$; (ii) $-\mathrm{z}+1 / 2,-\mathrm{x}+1 / 2$, y; (iii) $-\mathrm{x}+1 / 2, \mathrm{y},-\mathrm{z}+1 / 2$. $\alpha$ : dihedral angle between mean planes of the rings $\left({ }^{\circ}\right)$, DC: distance between ring centroids $(\AA), \beta$ : angle between DC vector and normal to plane $(\mathrm{I})\left(^{\circ}\right)$, DZ: perpendicular distance of the centroids of ring(I) on plane of ring(II) $(\AA)$, DXY: slippage $(\AA)$, Dist.: shorter distances between nonhydrogen atoms of rings (I) and (II). [b] Rings: 1A: C1A, C2A, C5A, C6A, C1A, C6A. 2A: C1B, C2B, C5B, C6B, C1B, C6B.

\section{S2. FT-IR spectroscopy.}

All spectra bear certain resemblance, finding the more significant difference for compound 1 given the absence of DMF molecules in its crystal structure. At high frequencies, they exhibit a broad and intense band below $3500 \mathrm{~cm}^{-1}$ that corresponds to the vibration of the $\mathrm{O}-\mathrm{H}$ bond of free water, followed by weak shoulders between 3215 and $3085 \mathrm{~cm}^{-1}$ corresponding to the $\mathrm{C}-\mathrm{H}$ vibrations of the DMF molecules. Vibrations of the $\mathrm{CN}$ groups of the ligand are the responsible for the weak bands peaking at around 2360,2330 , and $2235 \mathrm{~cm}^{-1}$. The intense vibrations in the $1690-1550 \mathrm{~cm}^{-1}$ region are attributed to both the asymmetric stretching vibrations of the carboxylate groups in addition to the aromatic $\mathrm{C}-\mathrm{C}$ bonds, while the symmetric stretching vibrations of the carboxylate groups appear in the lower range of $1405-1230 \mathrm{~cm}^{-1}$. At lower frequencies, the remaining bands are attributed to the distortions originated in the aromatic ring and the carboxylate groups of the CNip ligand. The vibration bands of the $\mathrm{M}-\mathrm{O}$ bonds are observed around $530 \mathrm{~cm}^{-1}$. 


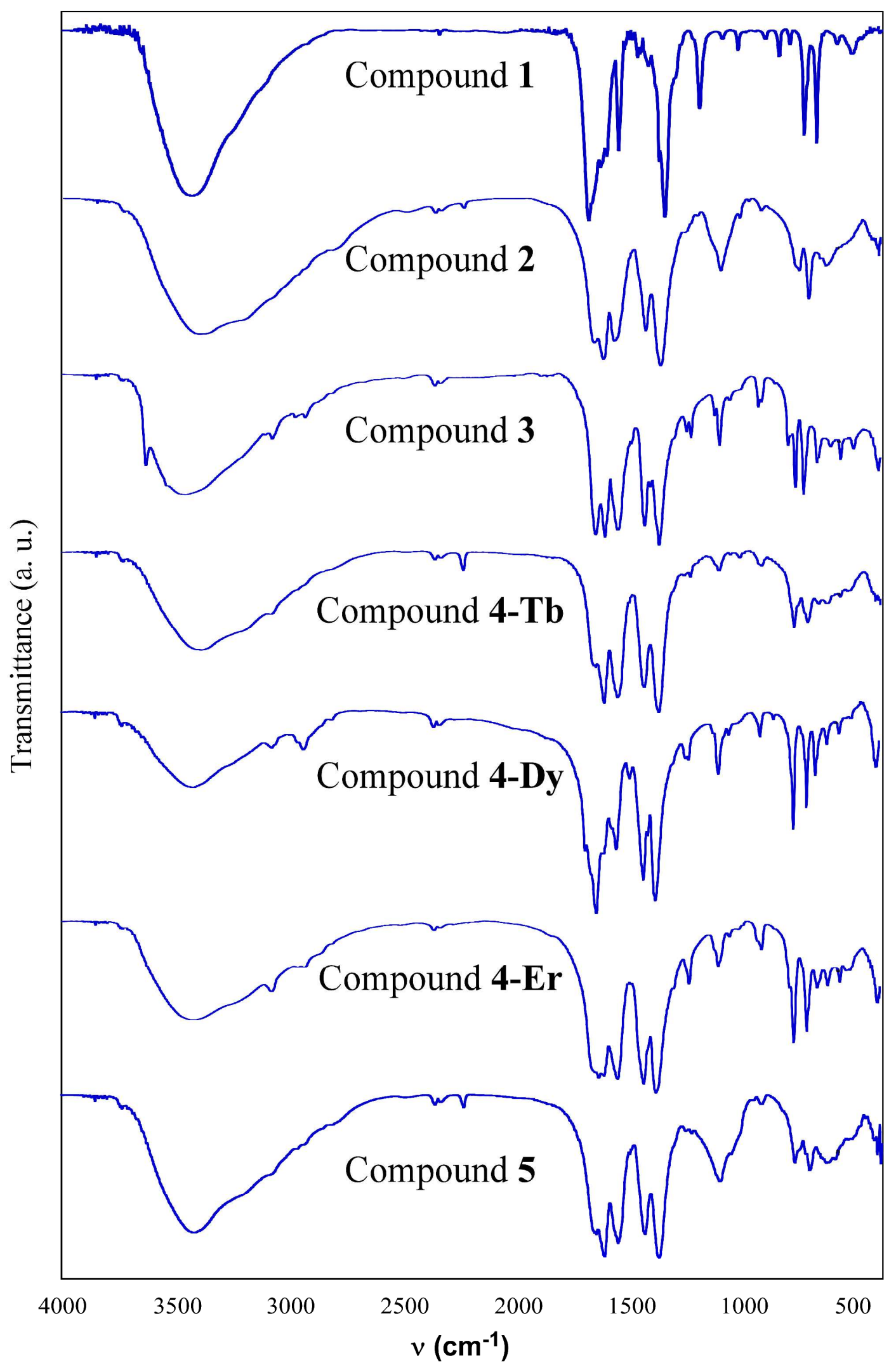

Figure S9. FTIR spectra of compounds 1-5. 


\section{S3. Thermogravimetric Analysis.}

Compound 1 shows a very slow release of the coordination water molecules up to 190 ${ }^{\circ} \mathrm{C}$ range, a step that is rapidly followed by the general decomposition of the compound after several exothermic processes. At $470{ }^{\circ} \mathrm{C}$ copper(II) oxide is obtained as final residue. TG curve of compound 2 reveals that the loss of crystallization solvent molecules takes place from room temperature up to $100{ }^{\circ} \mathrm{C}$, after which it starts the slow release of coordination molecules. This step leads to the general decomposition of the framework above $400{ }^{\circ} \mathrm{C}$, which involves a rapid mass loss and gives $\mathrm{Co}_{3} \mathrm{O}_{4}$ as final residue at $c a .500{ }^{\circ} \mathrm{C}$. Compound 3 remains somewhat stable upon heating from room temperature up to $80{ }^{\circ} \mathrm{C}$, where several endothermic processes associated with the release of the coordinated solvent molecules take place. The solvent loss finishes at 200 ${ }^{\circ} \mathrm{C}$ and the resulting product remains unchanged for almost $200{ }^{\circ} \mathrm{C}$. Above $400{ }^{\circ} \mathrm{C}$ it takes place the decomposition of the framework in such a way that CNip ligands are decomposed to lead to $\mathrm{CdO}$ as final residue at $c a .600^{\circ} \mathrm{C}$.
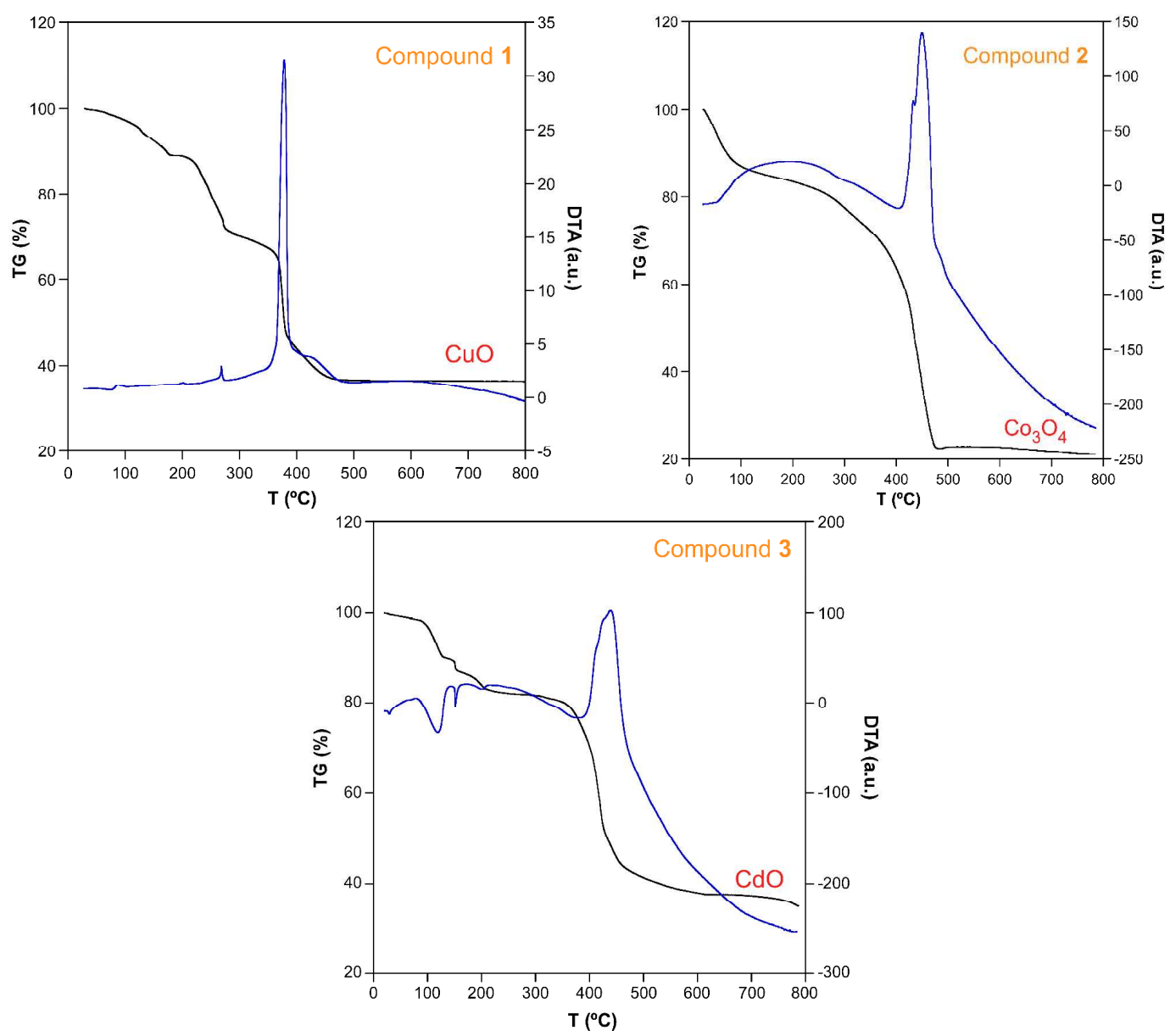

Figure S10. TG/DTA analysis for compounds 1-3. 
Compounds 4-Ln exhibit a very close thermal behavior so only that of 4-Dy is discussed in detail. Thermal analysis of 4-Dy compound shows that solvent molecules are released into two well separated steps. The first one, between room temperature and $90{ }^{\circ} \mathrm{C}$, accounts for the loss of crystallization DMF and $\mathrm{H}_{2} \mathrm{O}$ molecules together with two coordinated DMF molecules. Then, it takes place a second process in the TG curve that involves the release of the remaining two coordinated DMF molecules, which is completed at $280^{\circ} \mathrm{C}$. Upon heating, the organic molecules are immediately decomposed and $\mathrm{Dy}_{2} \mathrm{O}_{3}$ is rendered after several exothermic processes. Compound 5 presents a similar thermal behavior although the loss of crystallization and some of the coordination molecules (involving several endothermic processes within $30-150{ }^{\circ} \mathrm{C}$ range) cannot be distinguished. The TG curve levels off up to $265^{\circ} \mathrm{C}$, above which it starts decomposing to lead to $\mathrm{Gd}_{2} \mathrm{O}_{3}$ as final product at $c a .500{ }^{\circ} \mathrm{C}$.
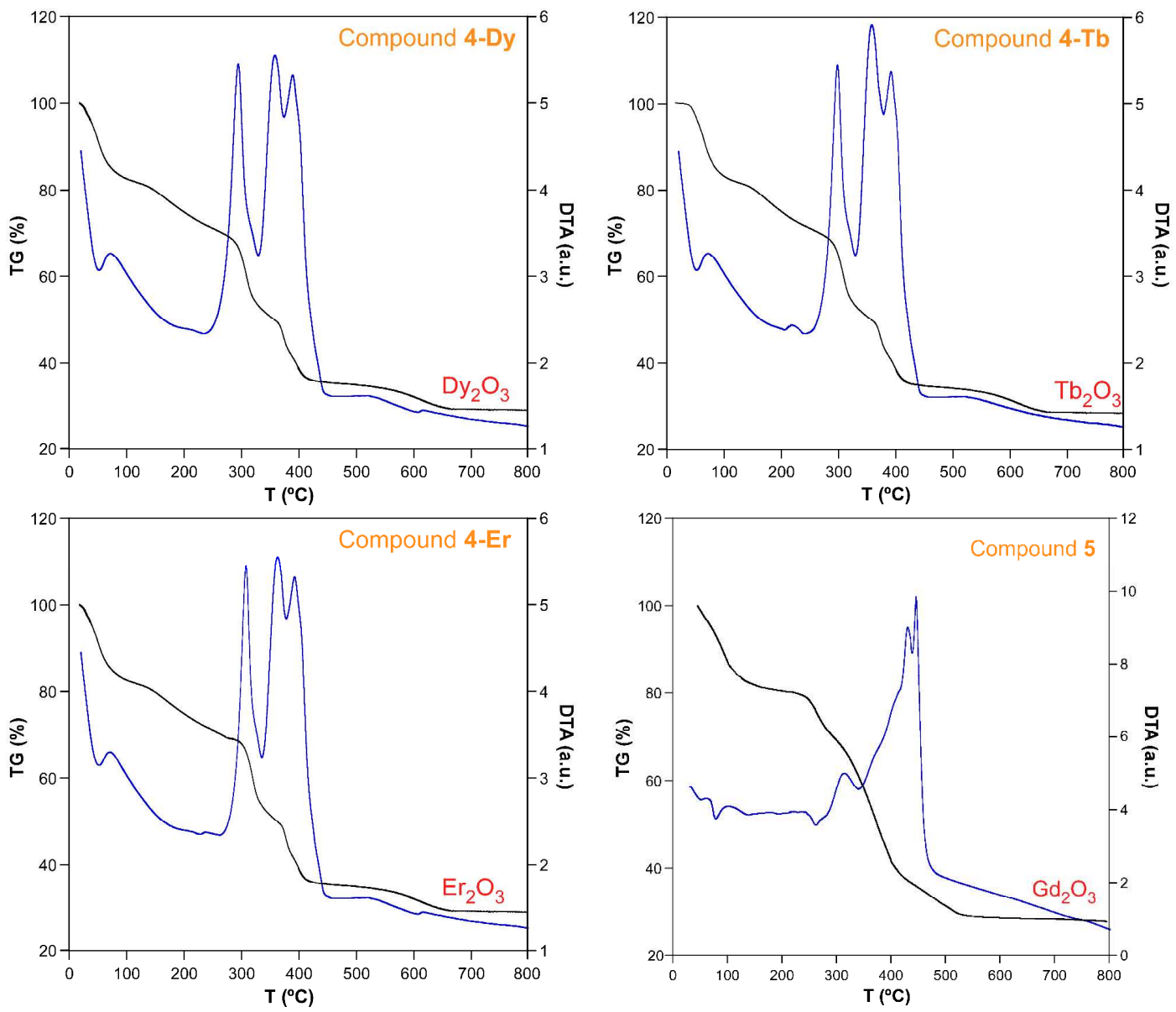

Figure S11. TG/DTA analysis for compounds 4-Ln and 5. 


\section{S4. Powder X-ray Diffraction Analysis.}

Pattern-matching analysis confirms the purity of the polycrystalline samples.

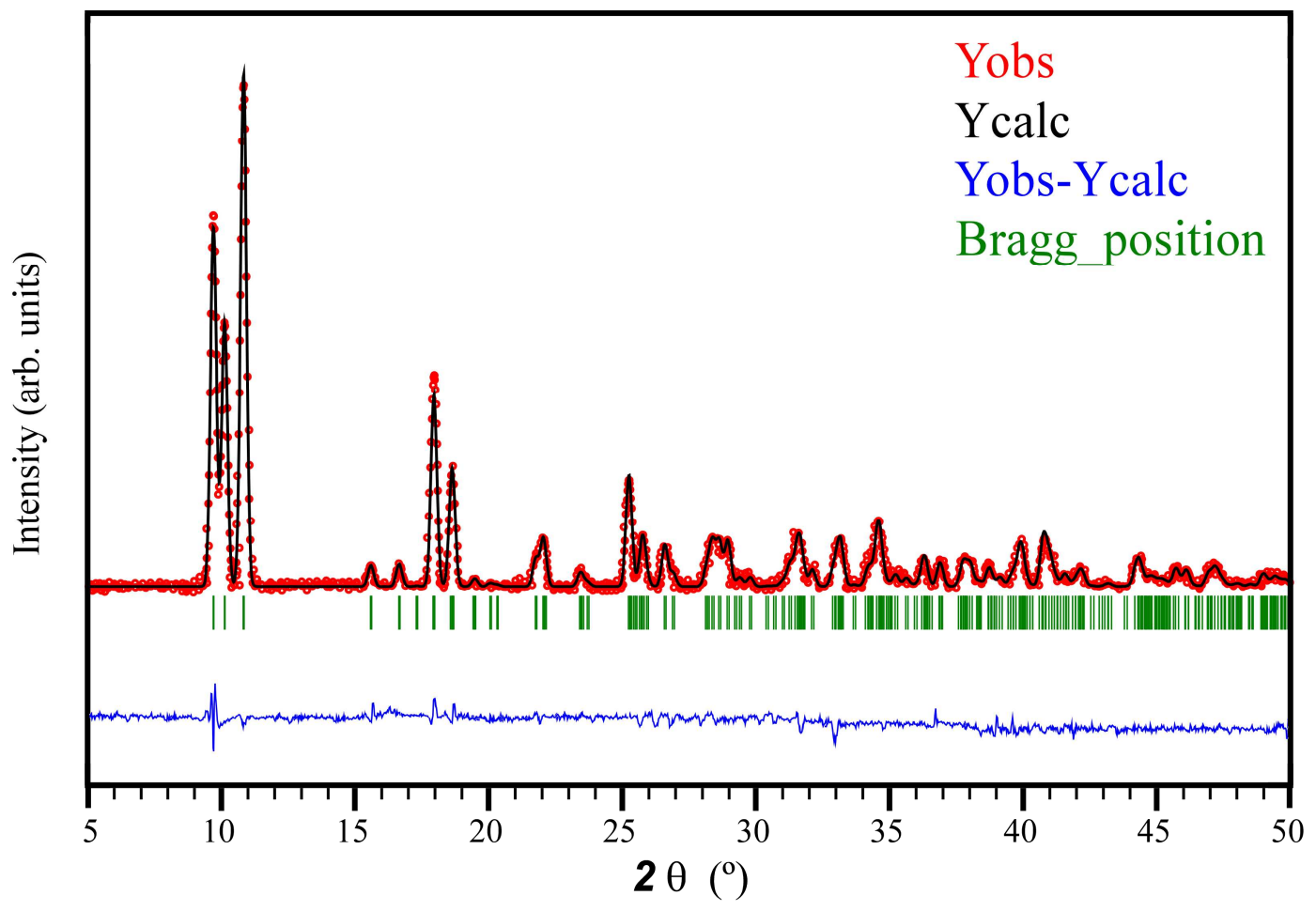

Figure S12. Pattern-matching analysis of polycrystalline sample of compound $\mathbf{1 .}$

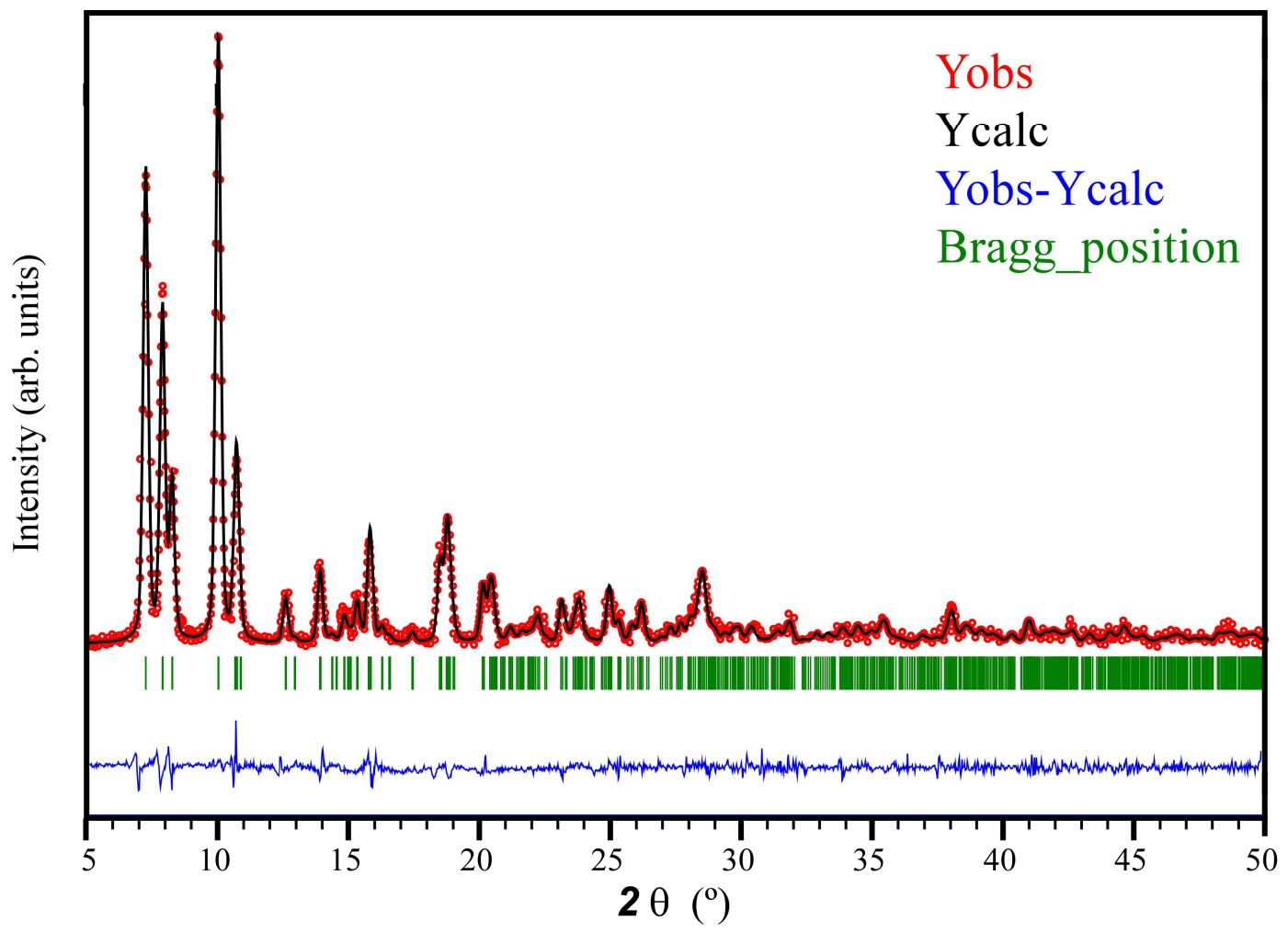

Figure S13. Pattern-matching analysis of polycrystalline sample of compound $\mathbf{2}$. 


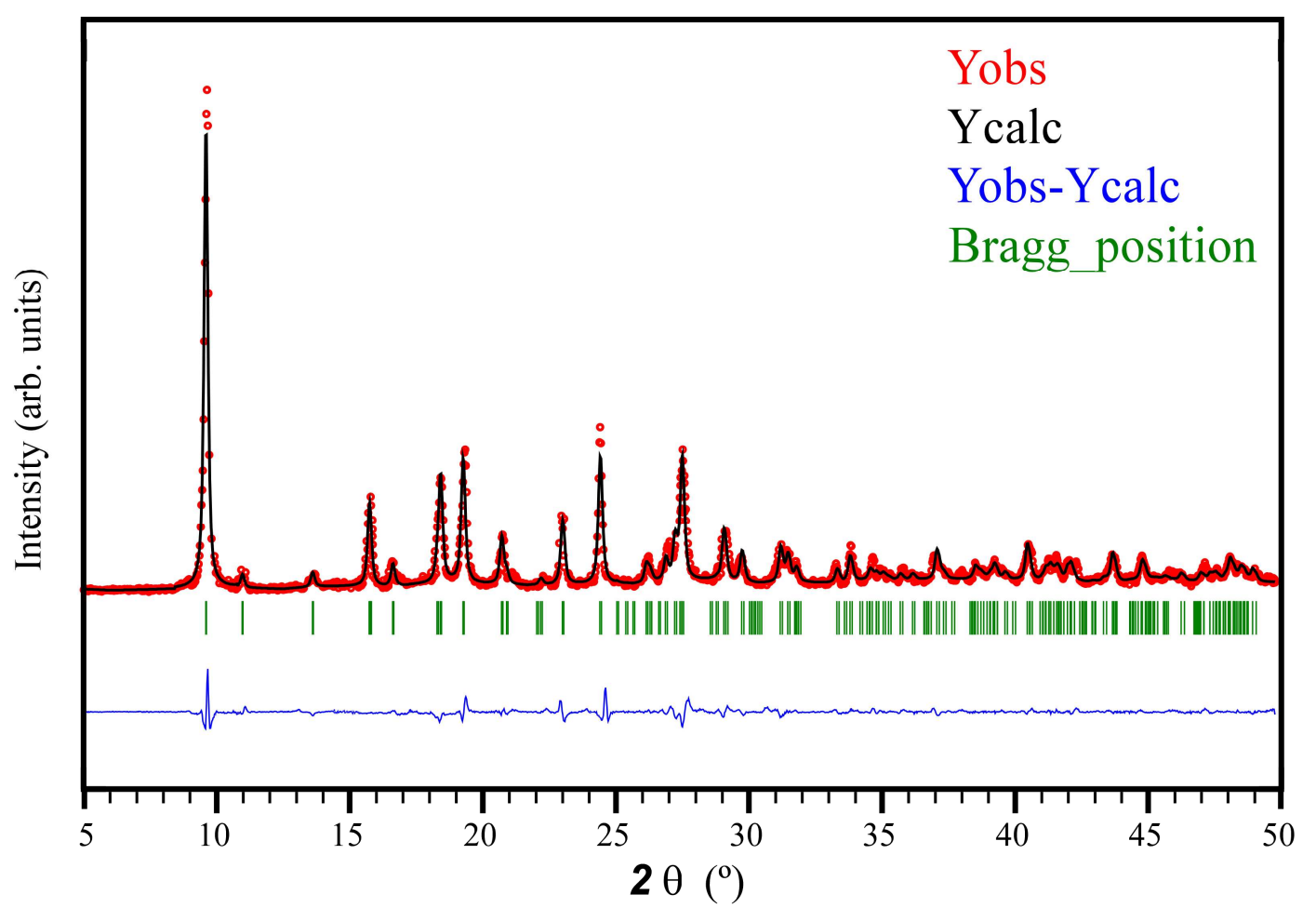

Figure S14. Pattern-matching analysis of polycrystalline sample of compound $\mathbf{3}$.

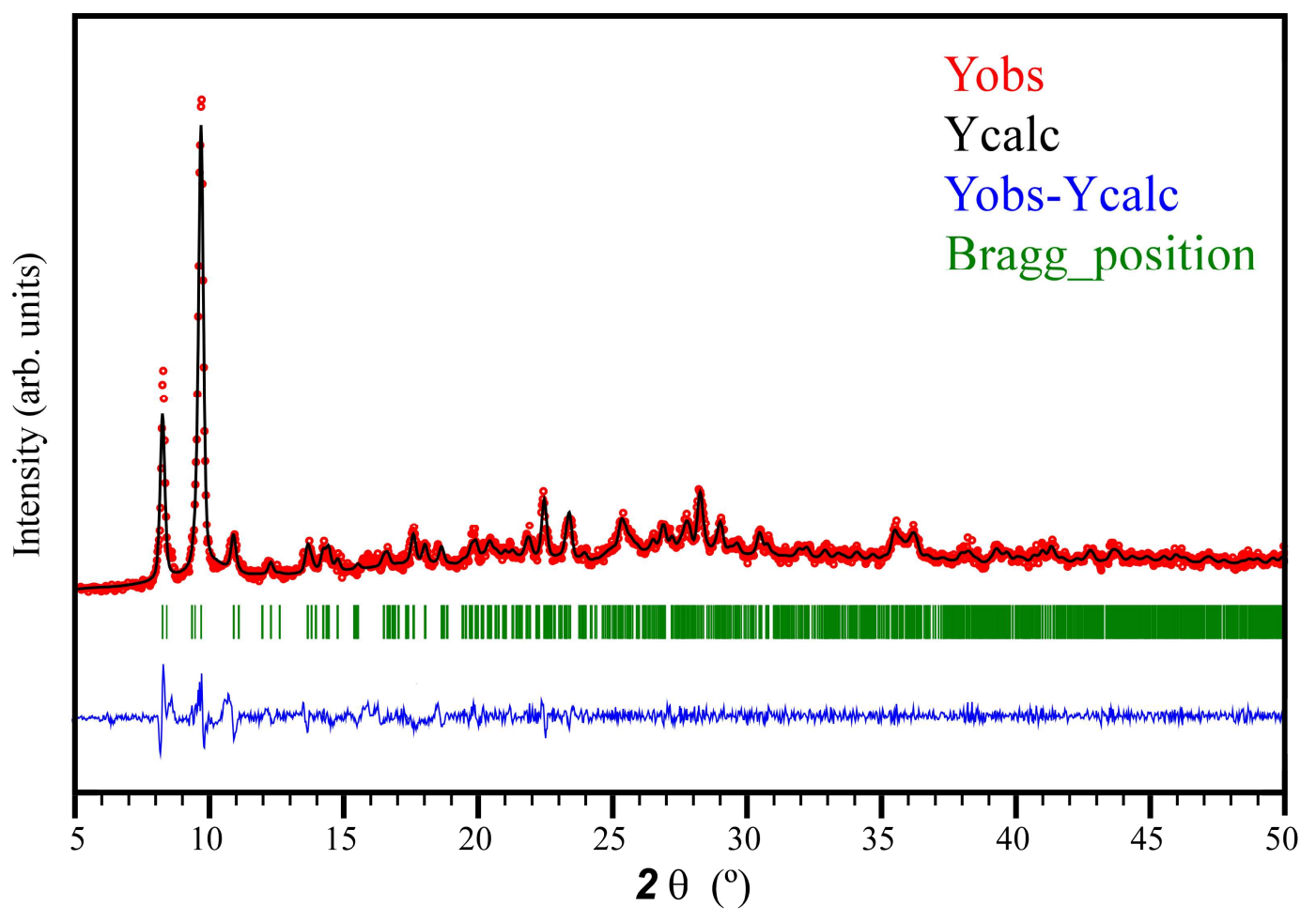

Figure S15. Pattern-matching analysis of polycrystalline sample of compound 4-Dy. 


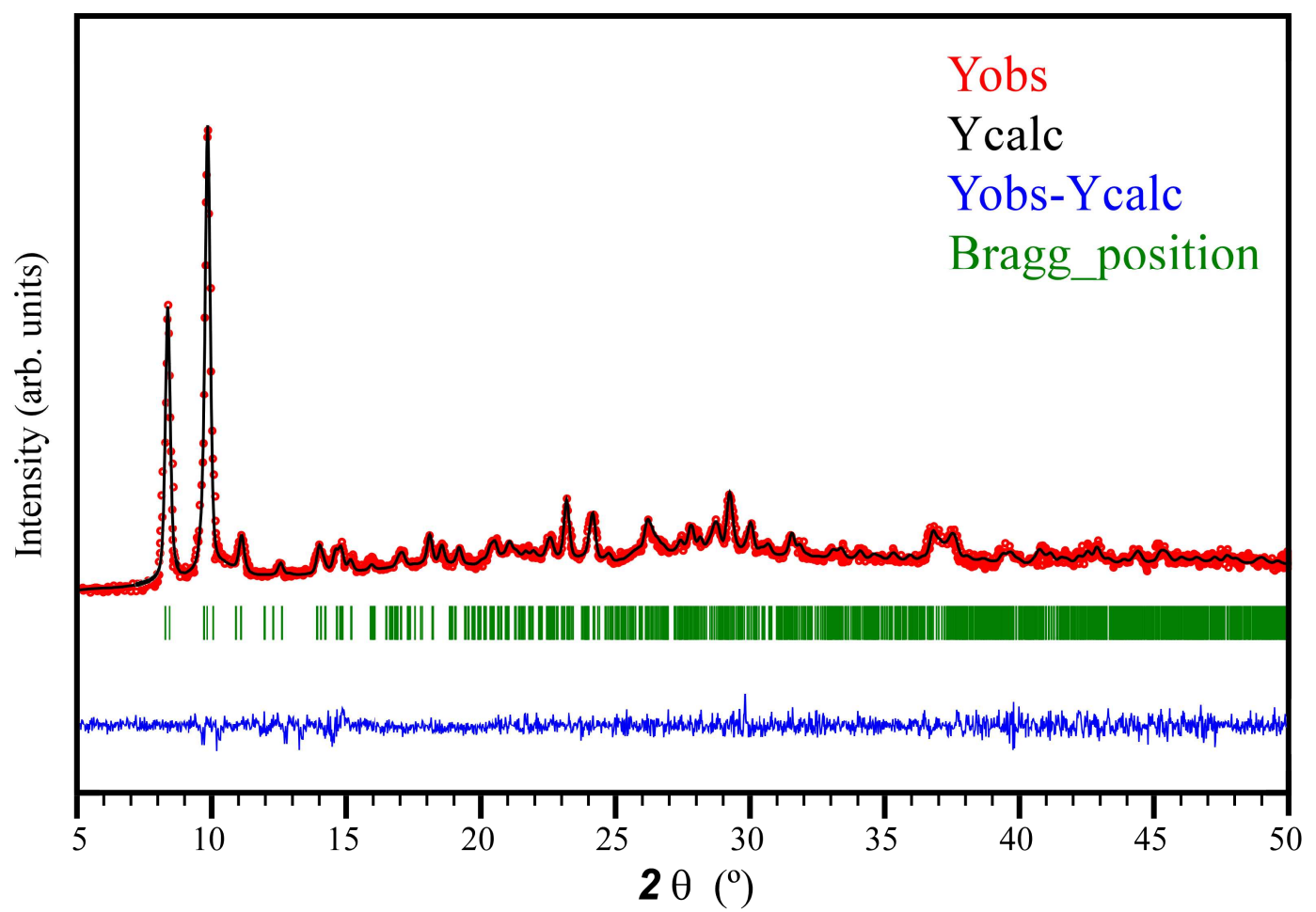

Figure S16. Pattern-matching analysis of polycrystalline sample of compound 4-Tb.

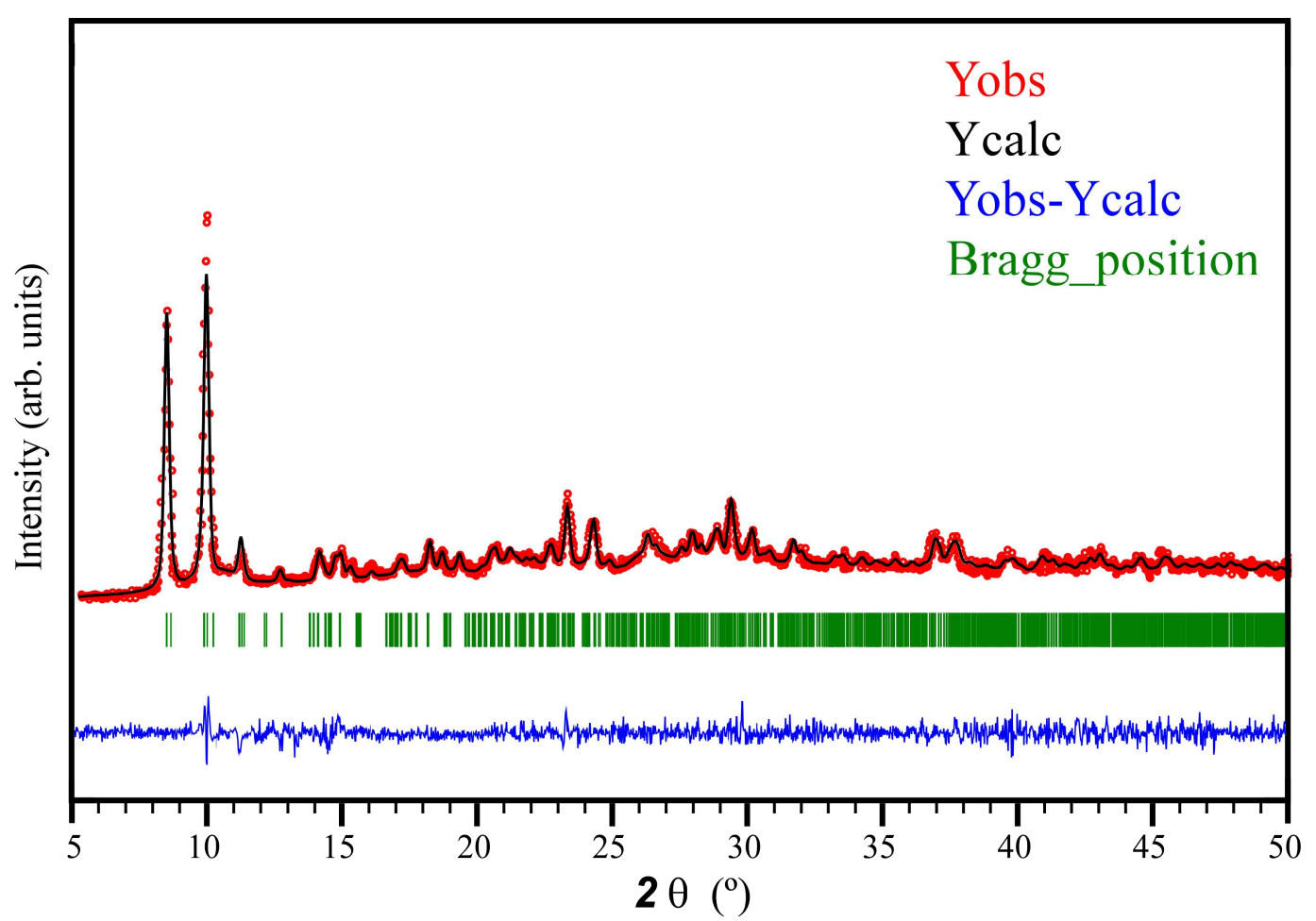

Figure S17. Pattern-matching analysis of polycrystalline sample of compound 4-Er. 


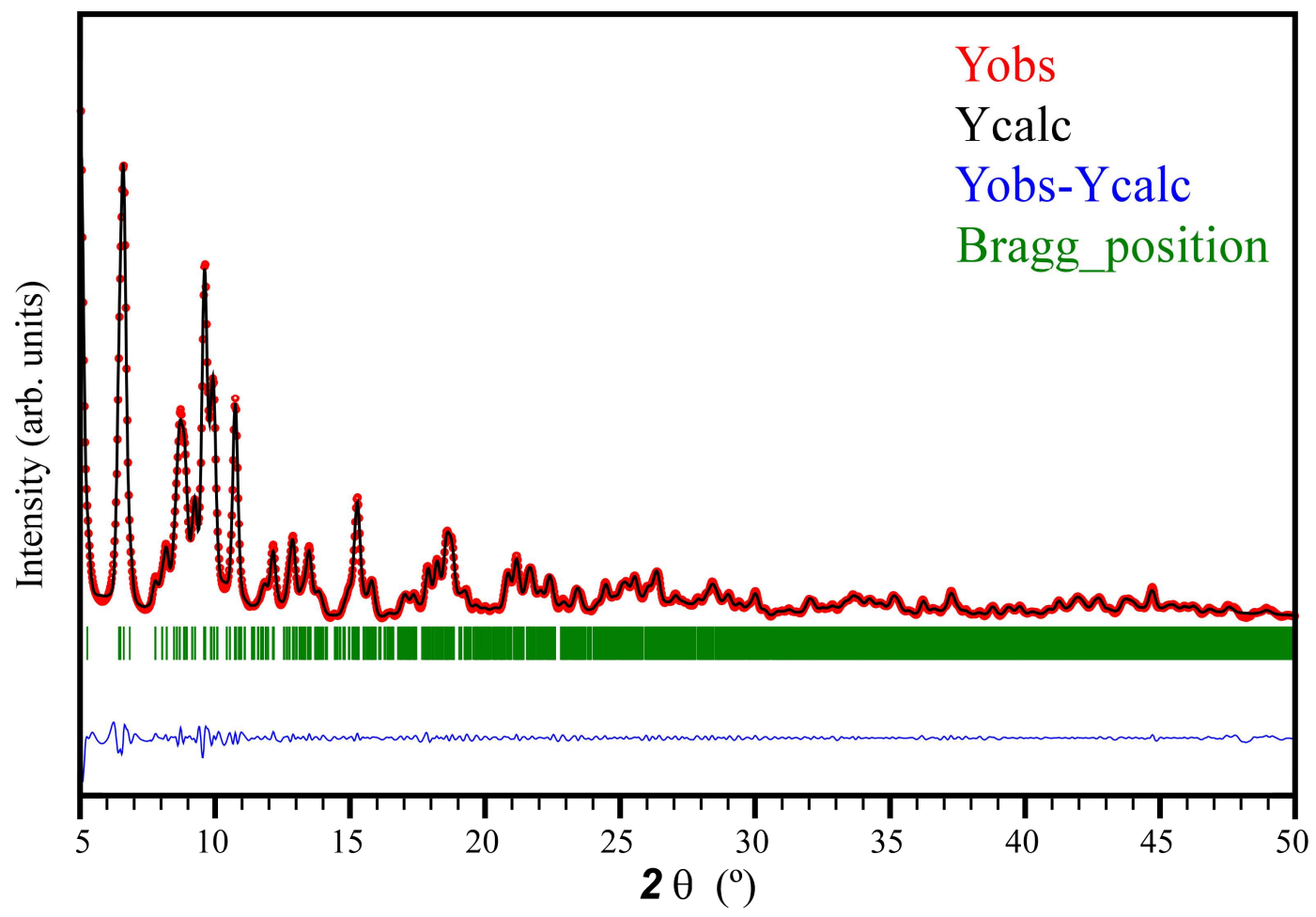

Figure S18. Pattern-matching analysis of polycrystalline sample of compound $\mathbf{5}$. 
S5. Ac susceptibility measurements.
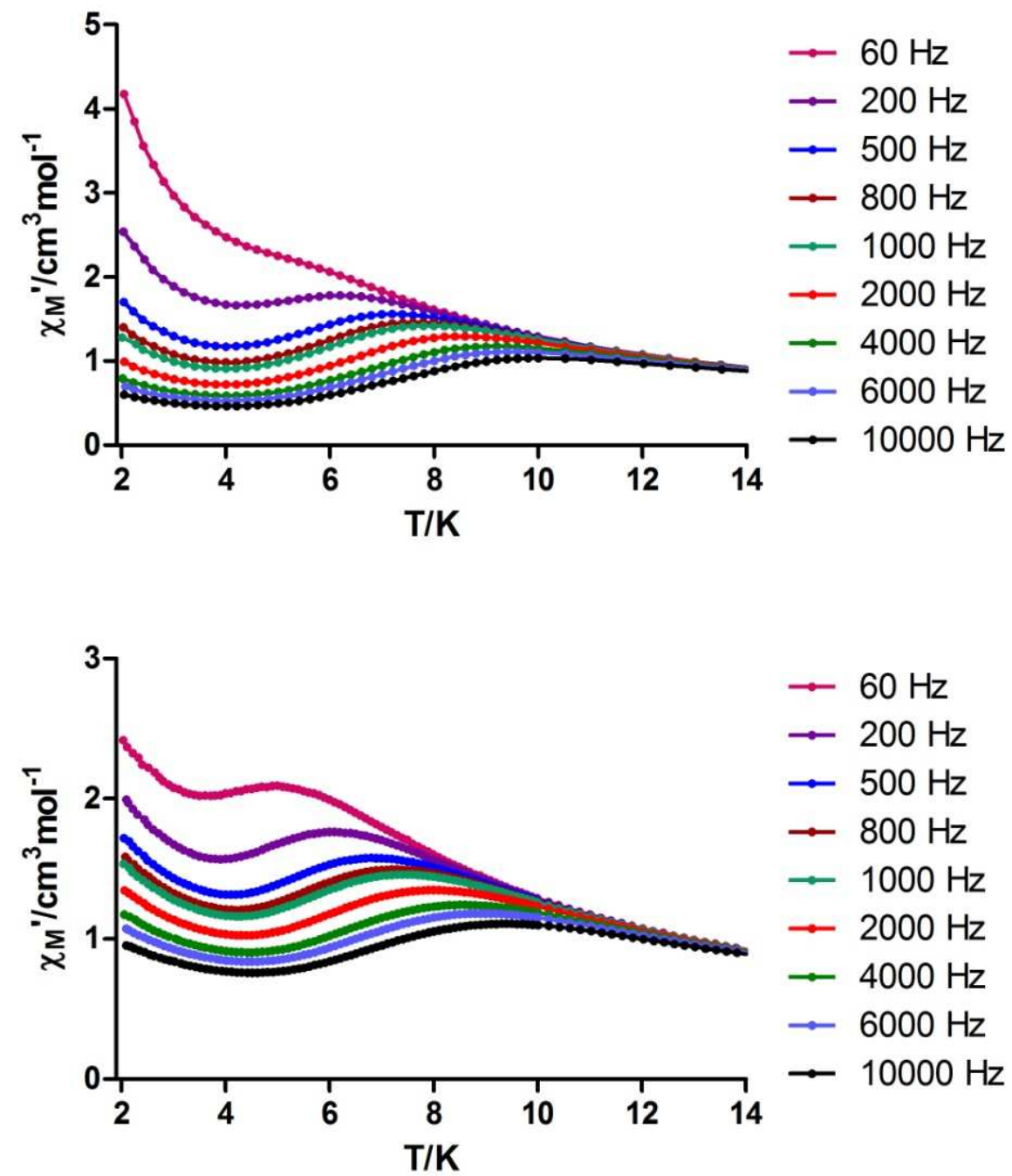

Figure S19. Temperature dependence of the in-phase $\chi_{M}{ }^{\prime}$ signals for complex 4-Dy in zero (top) and 1000 Oe (bottom) applied fields. 

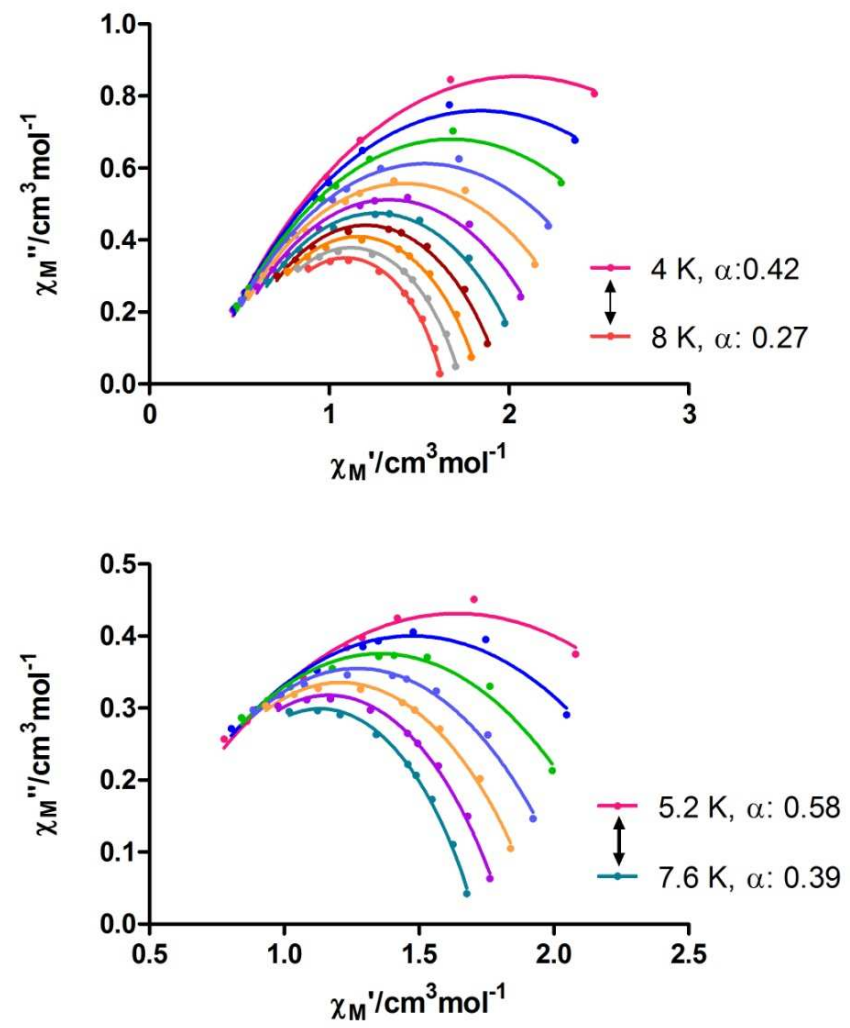

Figure S20. Cole-Cole plots for complex 4-Dy in zero (top) and 1000 Oe (bottom) applied fields.
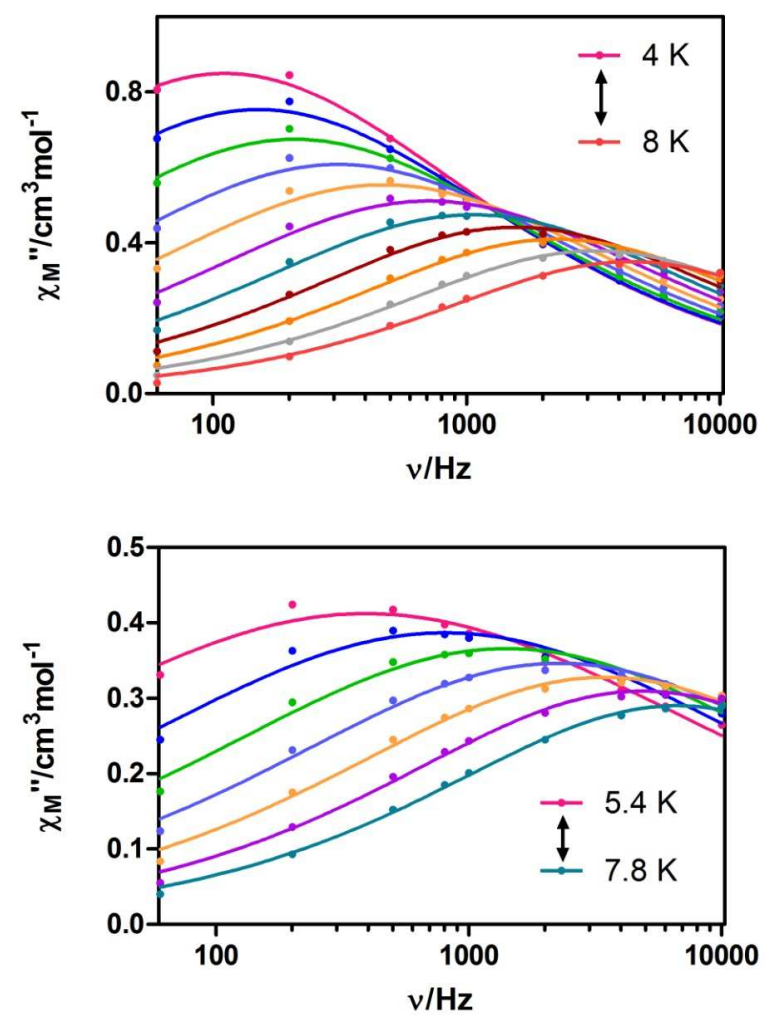

Figure S21. Variable-temperature frequency dependence of the $\chi_{M}$ " signal for complex 4-Dy in zero (top) and 1000 Oe (bottom) applied fields. 

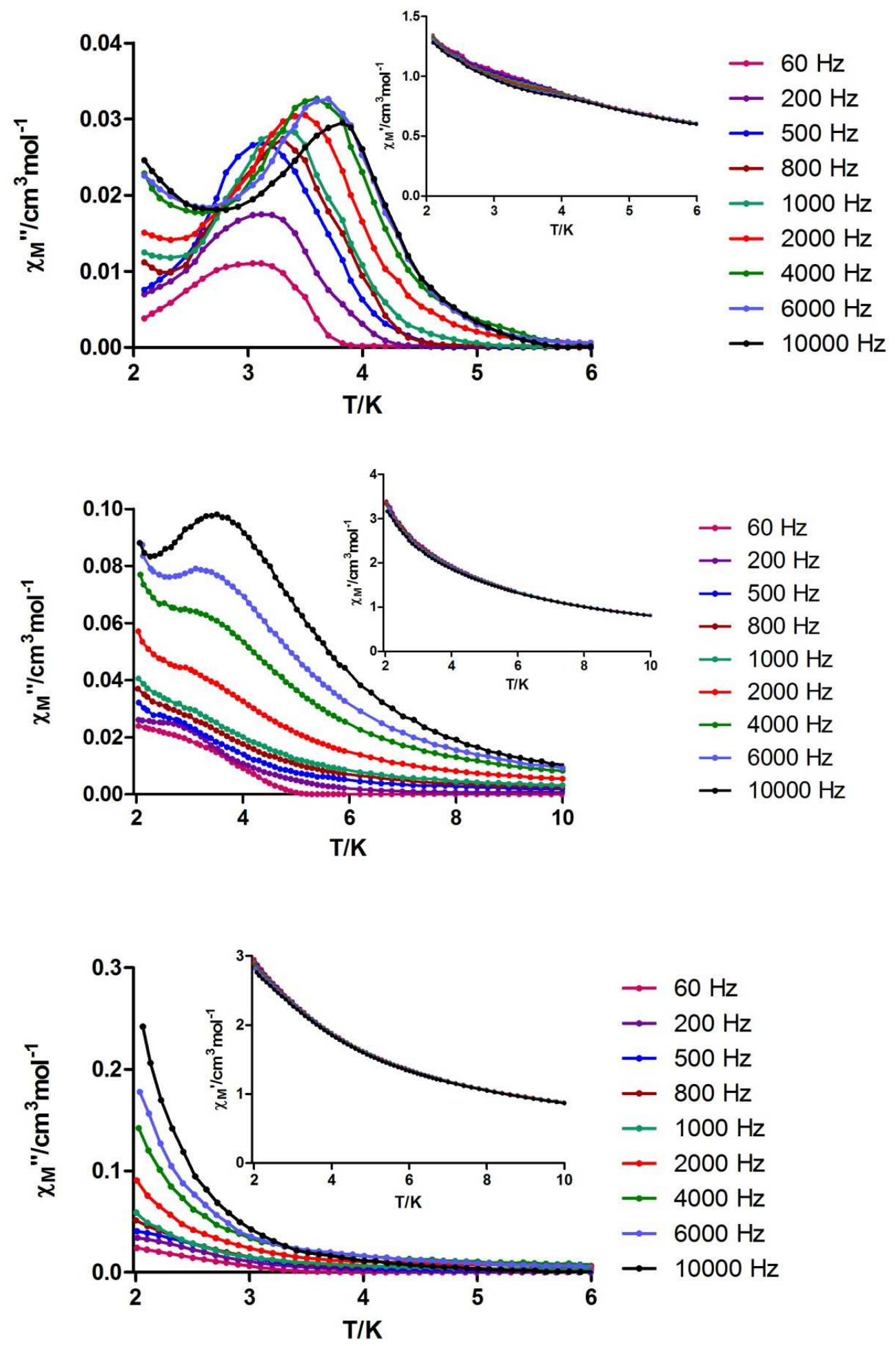

Figure S22. Temperature dependence of the in-phase $\chi_{M}$ ' (insets) and out-of-phase $\chi_{M}$ " signals for complexes 2, 4-Er and 5 under 1000 Oe applied fields. 


\section{S6. Spin densities of broken symmetry calculations.}

Calculations of the coupling constants through the broken symmetry strategy for all compounds have been performed upon models based on dimeric entities grown from crystallographic coordinates of X-ray crystal structures. Bridging and terminal ligands have been simplified replacing them by simpler molecules. For instance, bridging carboxylate CNip ligands have been replaced by acetate ligands and dimethylformamide by water molecules.
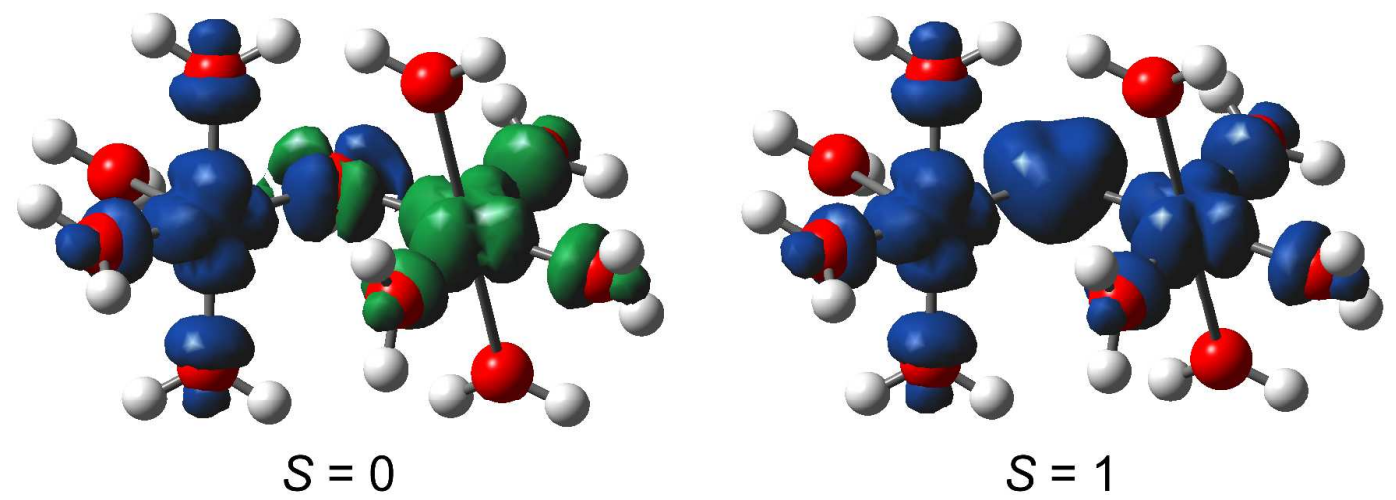

Figure S23. Calculated low and high spin density distributions for the simple superexchange pathway for model 1.

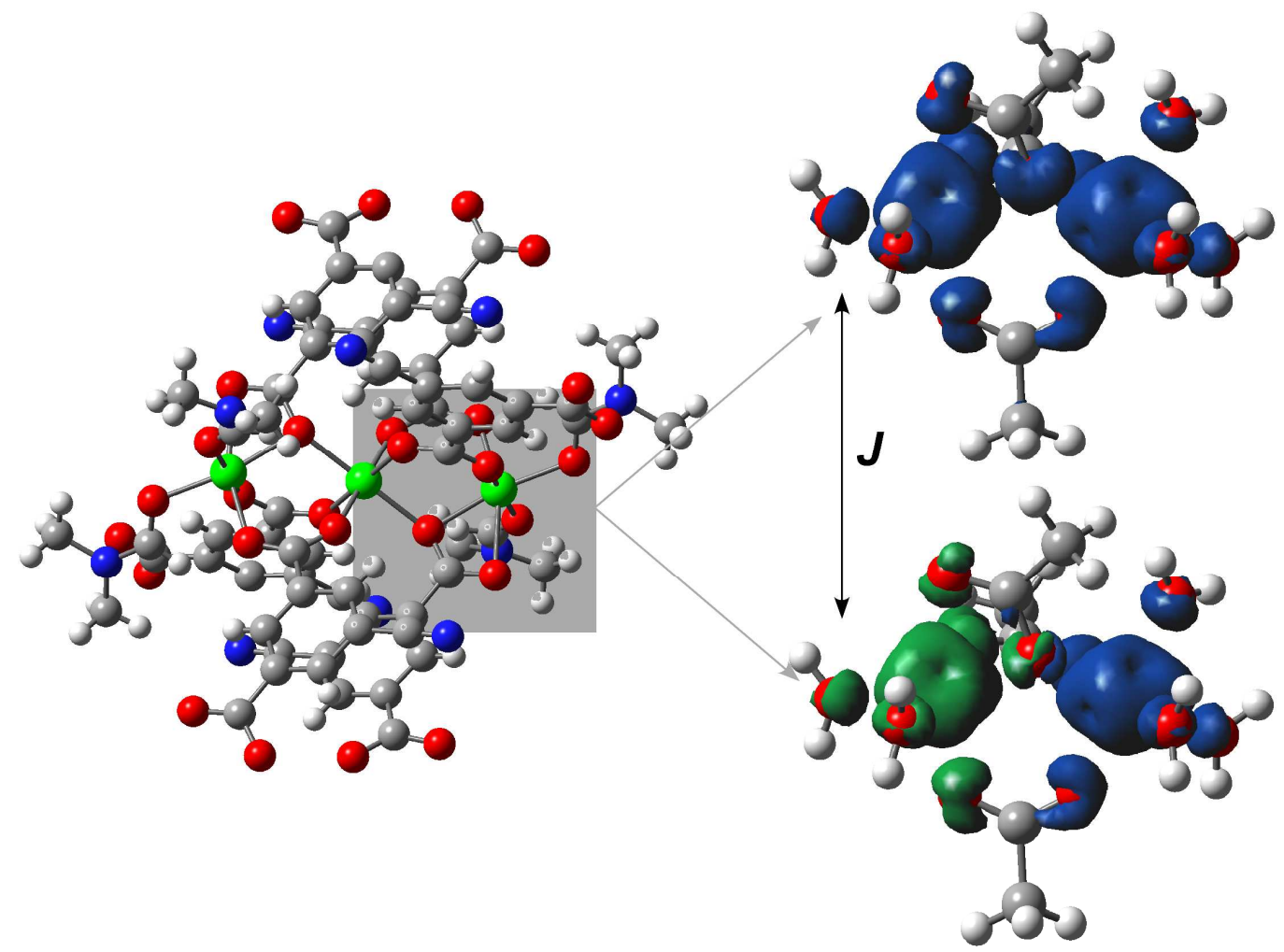

Figure S24. Calculated spin density distributions for model $\mathbf{2}$ in which one of the two symmetric superexchange pathways is computed. 

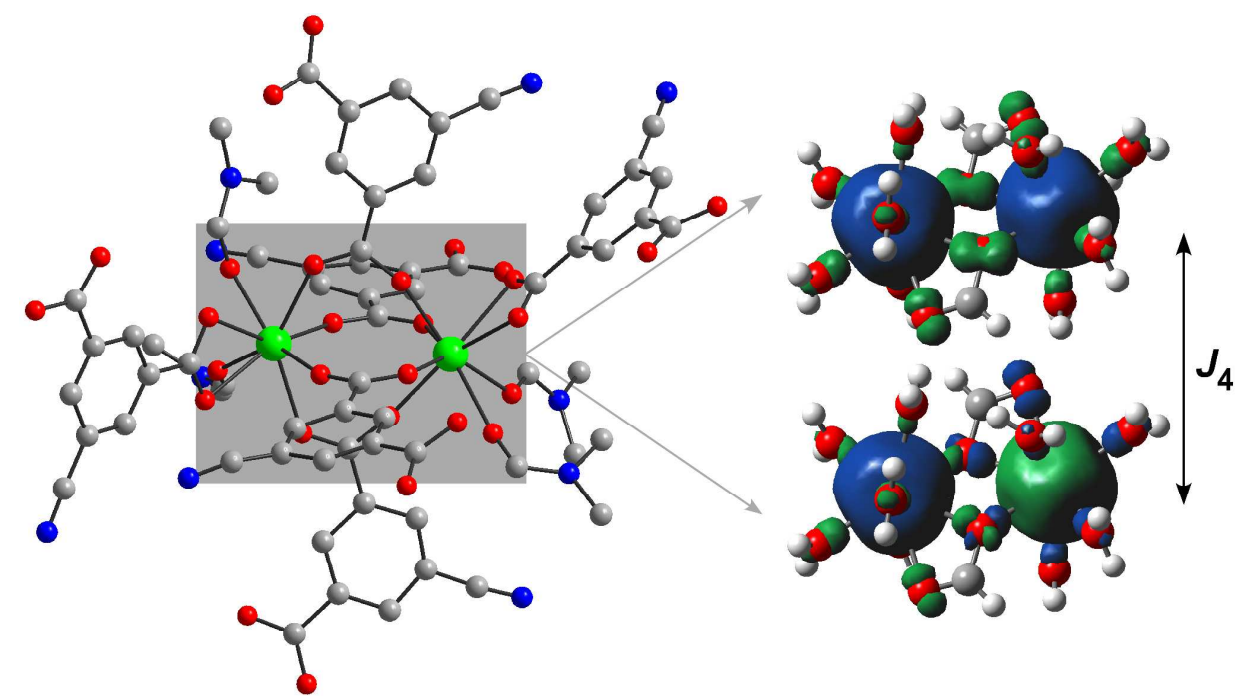

Figure S25. Calculated spin density distributions for the dimeric entity of model 5 for the highspin and broken-symmetry states.

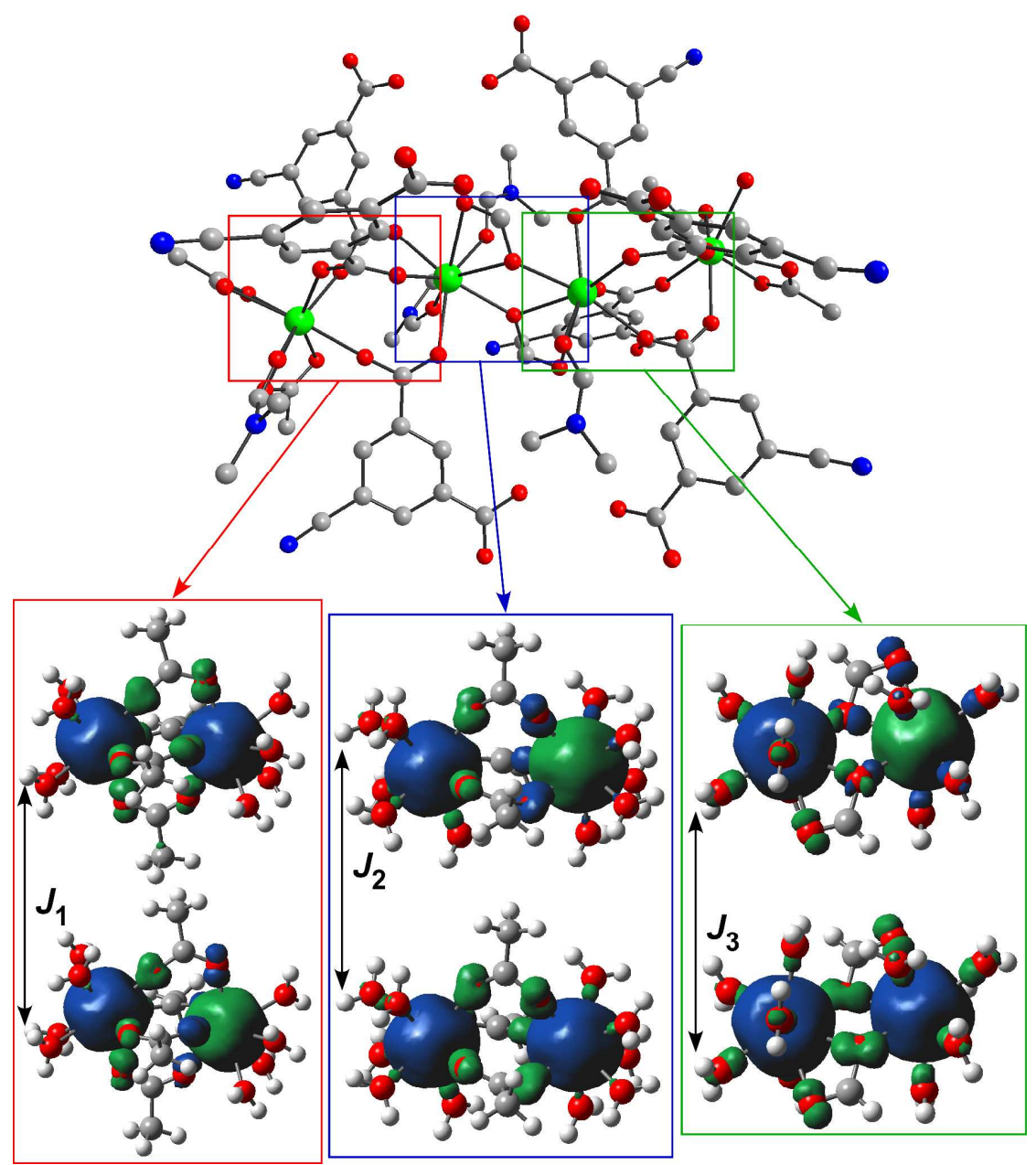

Figure S26. Calculated spin density distributions for the three computed superexchange pathways considered on the tetrameric unit of model $\mathbf{5}$. 
S7. Adsorption measurements.

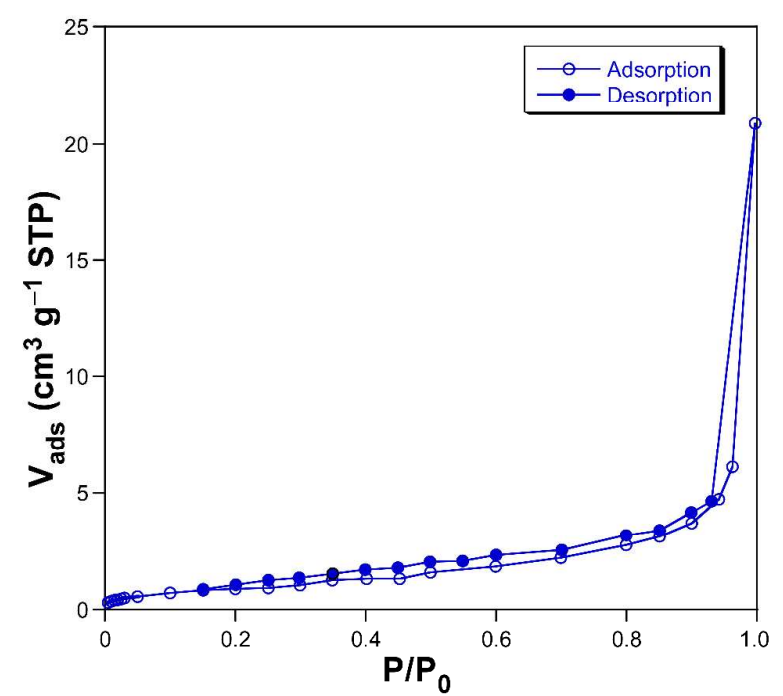

Figure S27. $\mathrm{N}_{2}$ adsorption and desorption curves at $77 \mathrm{~K}$ for 4-Dy compound.

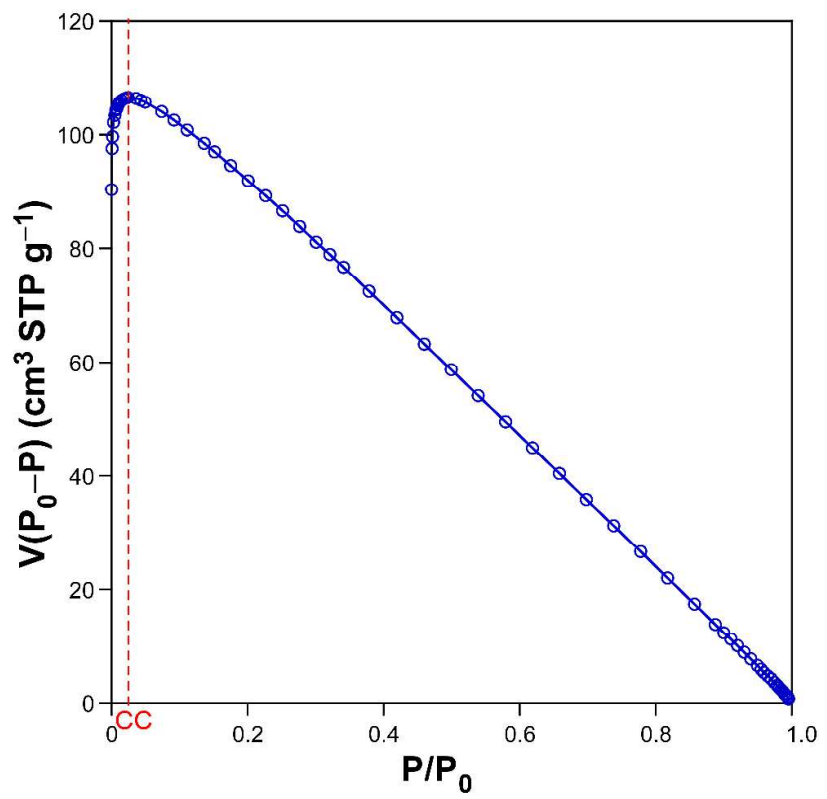

Figure S28. Plot of $\mathrm{N}_{2}$ adsorption for compound $\mathbf{5}$ showing the limit relative pressure according to consistency criterion. 
S8. Photoluminescence spectra.

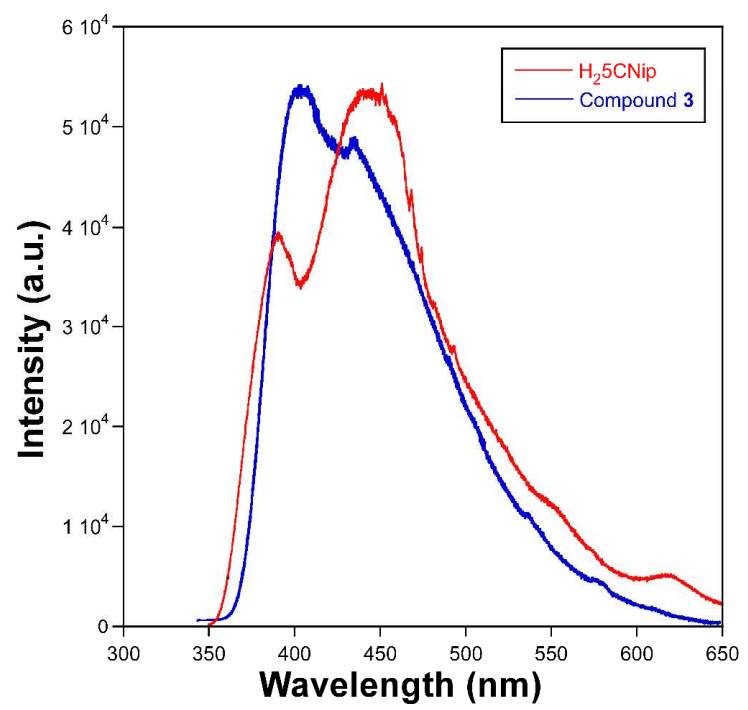

Figure S29. Emission spectra of compound $\mathbf{3}$ and $\mathrm{H}_{2} \mathrm{CNmbdc}$ ligand.
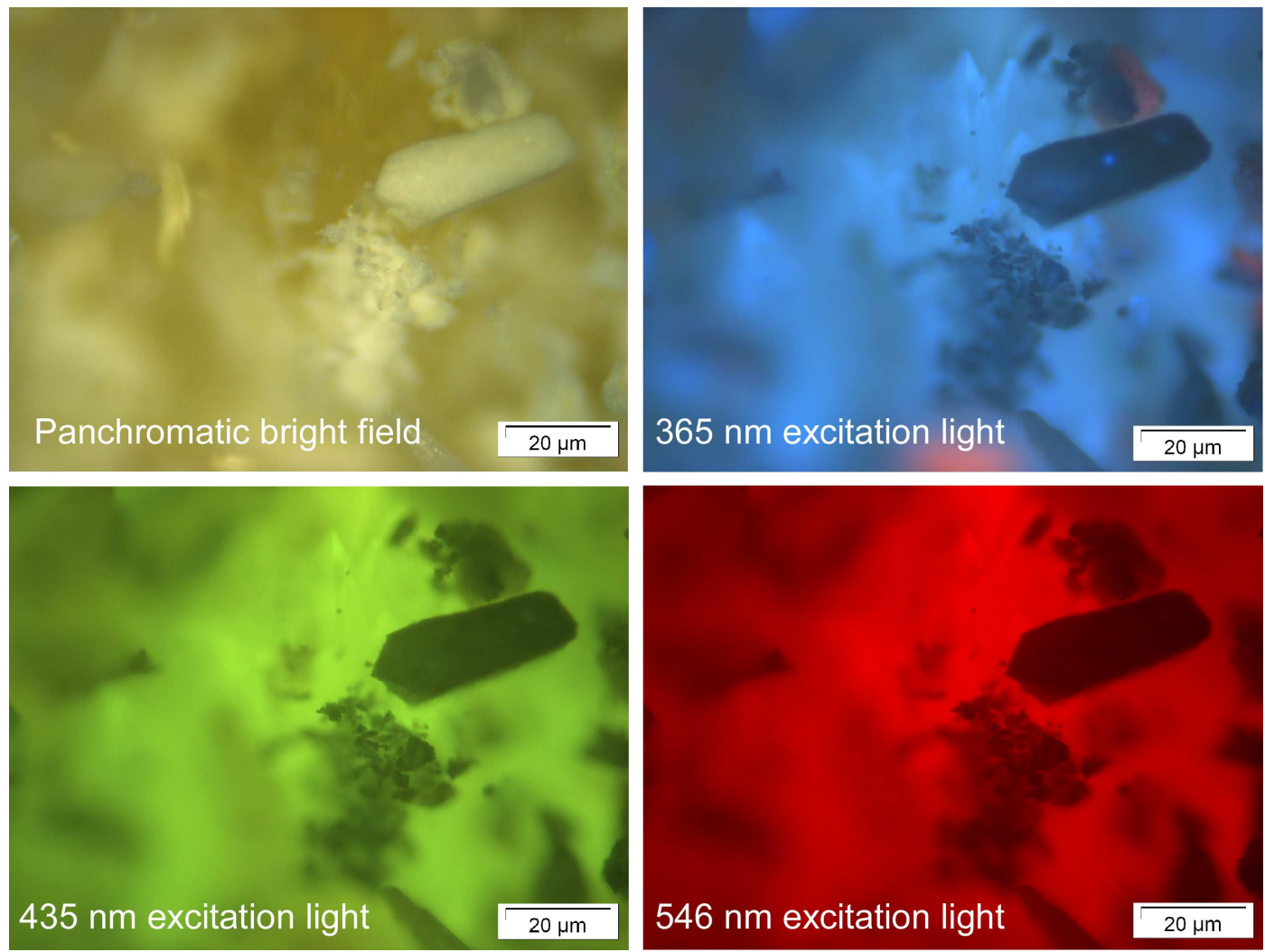

Figure S30. Room temperature micro-photoluminescence images taken at polycrystalline sample of compound $\mathbf{3}$ under different excitation beams. 


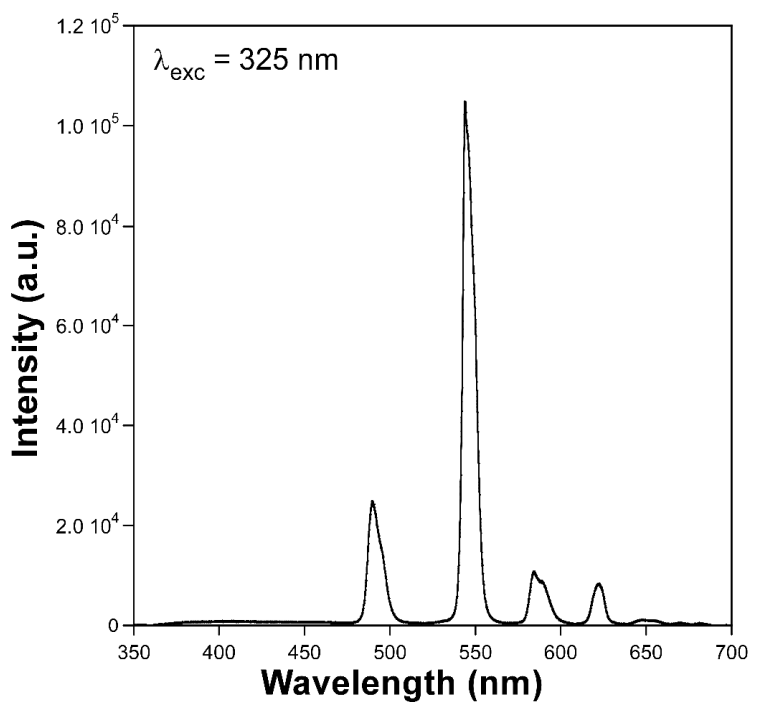

Figure S31. Room temperature emission spectrum of compound 4-Tb.

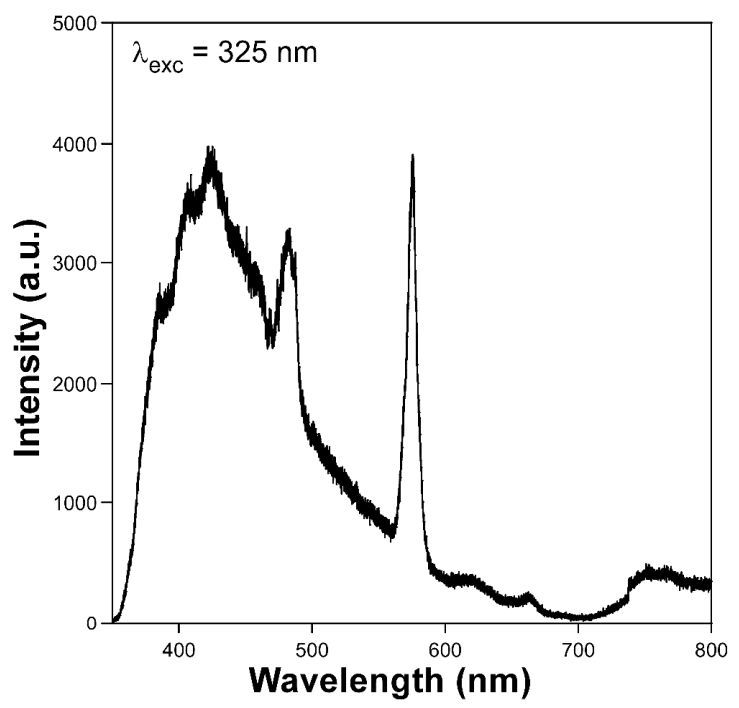

Figure S32. Room temperature emission spectrum of compound 4-Dy.

\section{S9. Photoluminescence lifetimes.}

Emission decay curve was measured for 3 at the emission maximum $(\lambda=400 \mathrm{~nm})$. Experimental lifetime was obtained by deconvoluting the pulse signal according to Intrument Response Functions (IRF) at the same working conditions. The spectrum was recorded by exposing the sample for several hours given the poor intensity of the emission.

With regard to 4-Tb and 4-Dy compounds, decay curves were measured with a microsecond pulse lamp, from which lifetime values were analyzed by tail fitting. 


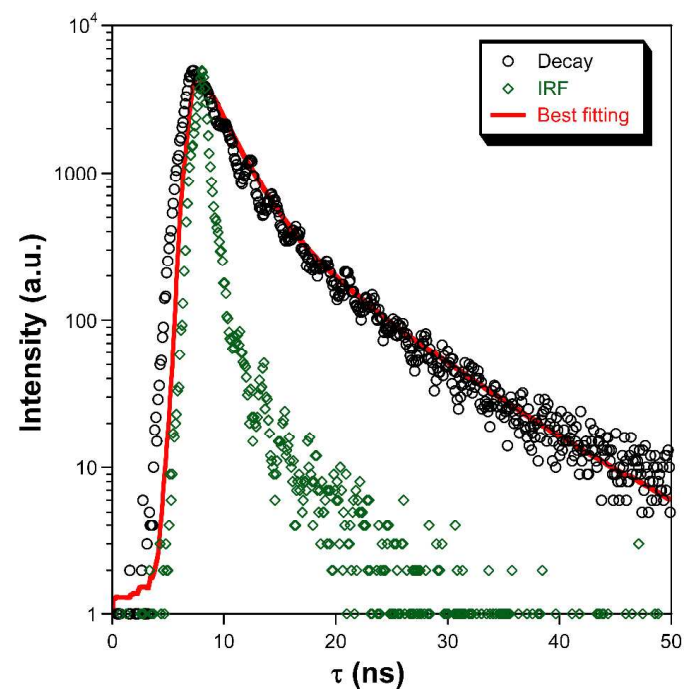

Figure S33. Emission decay curve showing the best fitting together with the Instrumental Reference File (IRF) of the employed nanosecond pulse lamp.
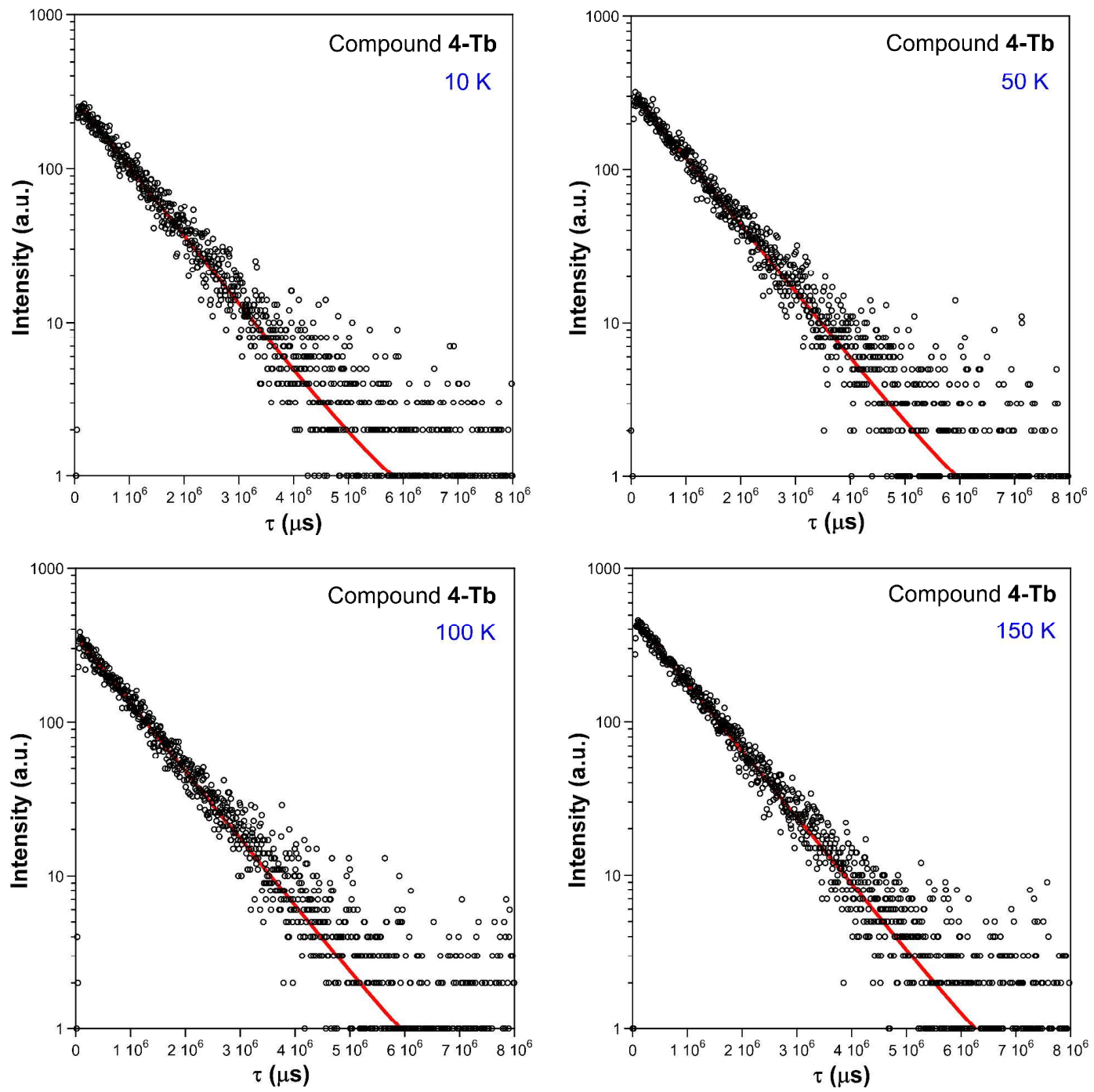

Figure S34. Luminescence decay lifetime fits of 4-Tb monitored at ${ }^{5} \mathrm{D}_{4} \rightarrow{ }^{7} \mathrm{~F}_{5}$ transition. 

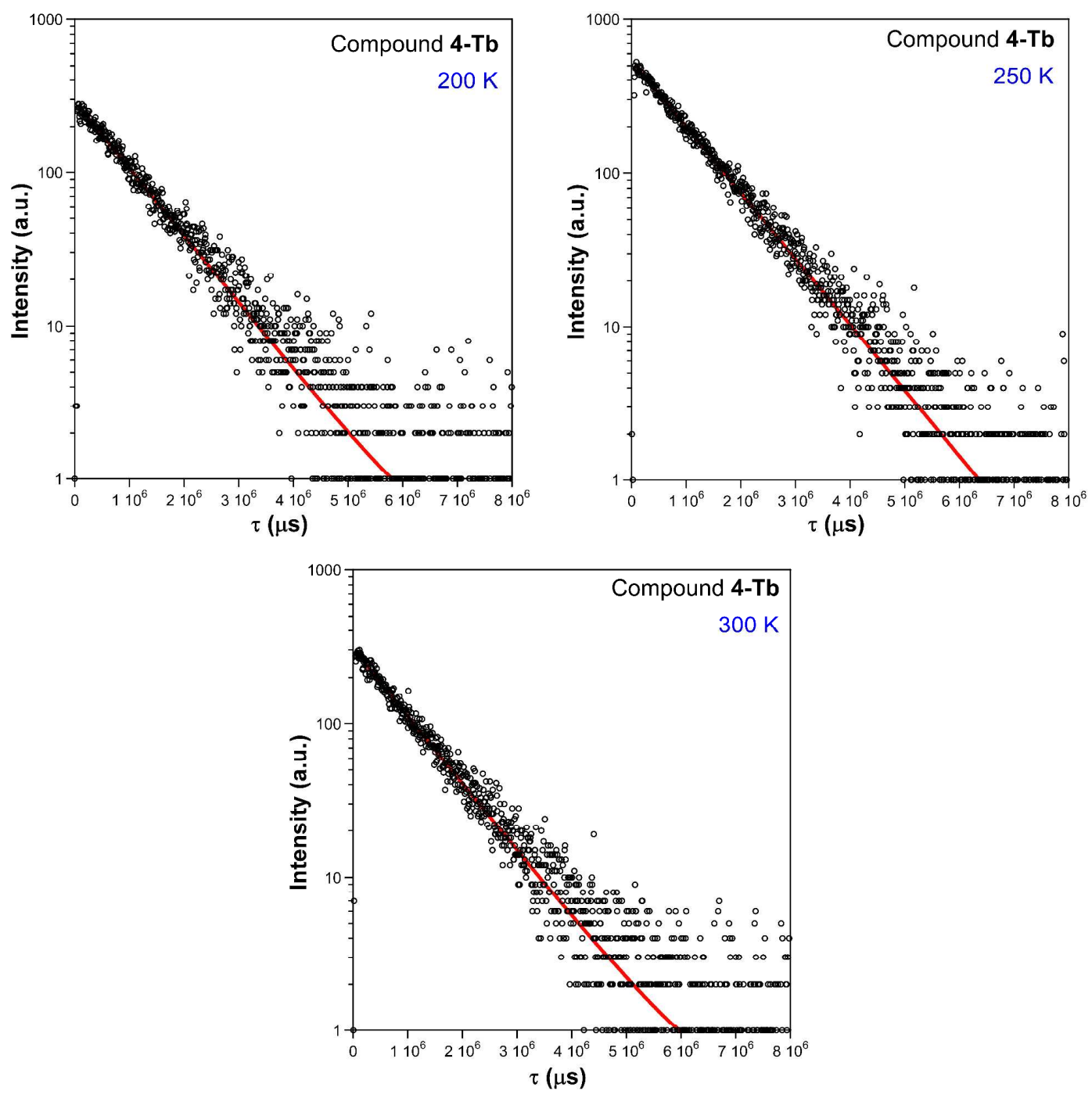

Figure S34. Luminescence decay lifetime fits of 4-Tb monitored at ${ }^{5} \mathrm{D}_{4} \rightarrow{ }^{7} \mathrm{~F}_{5}$ transition (cont.).
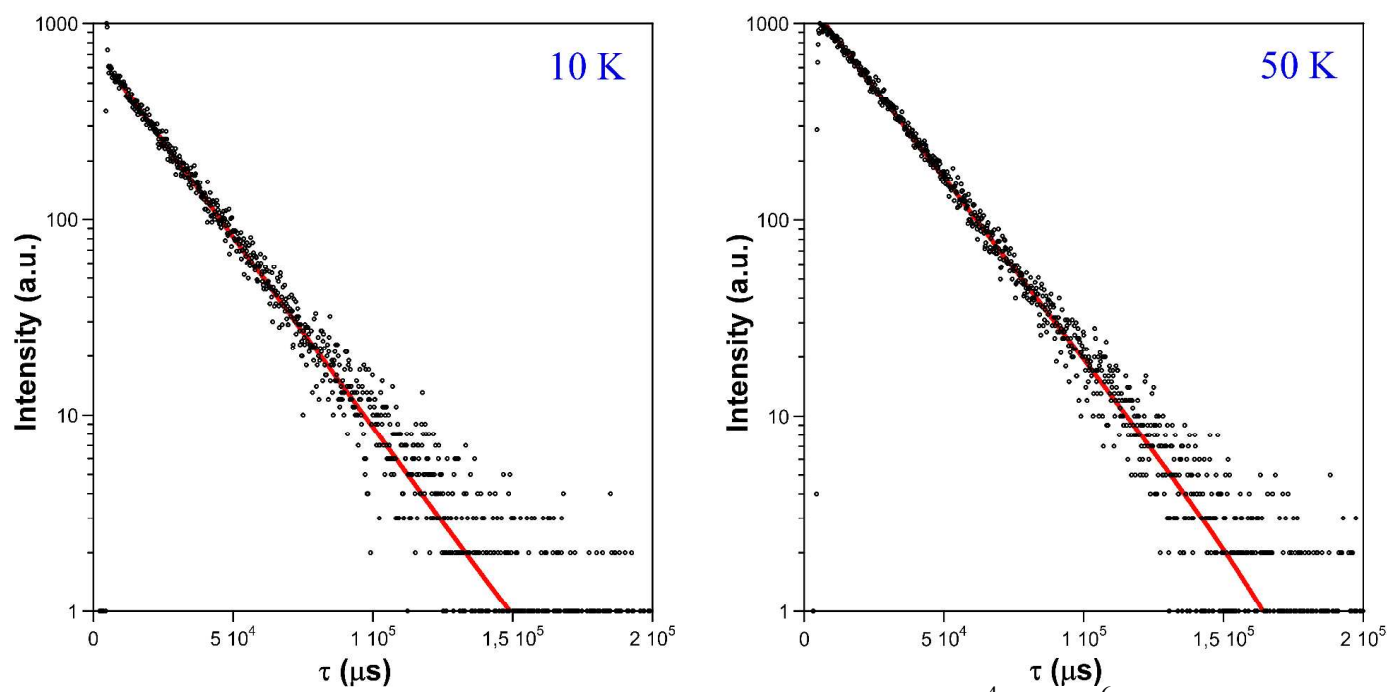

Figure S35. Luminescence decay lifetime fits of 4-Dy monitored at ${ }^{4} \mathrm{~F}_{9 / 2} \rightarrow{ }^{6} \mathrm{H}_{15 / 2}$ transition. 

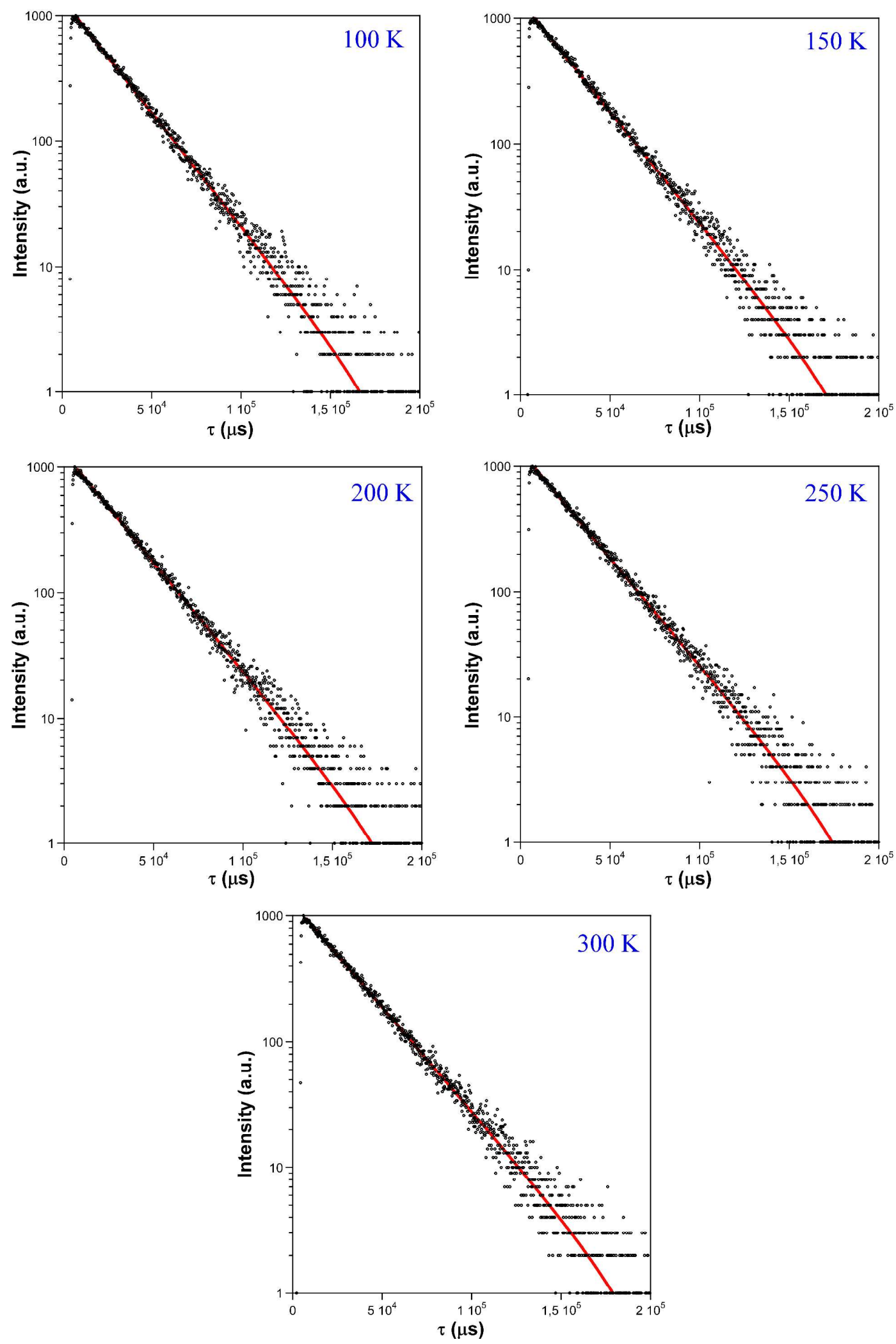

Figure S35. Luminescence decay lifetime fits of 4-Dy monitored at ${ }^{4} \mathrm{~F}_{9 / 2} \rightarrow{ }^{6} \mathrm{H}_{15 / 2}$ transition (cont.). 


\section{S10. TD-DFT computational results.}

A suitable model of $\mathbf{3}$ (model $\mathbf{3}$ hereafter) was built from the X-ray single crystal structure of $\mathbf{3}$, which consists of an excerpt that contains the ligands whose donor atoms establish the first coordination sphere of the metal. Given the large charge remaining in this complex, all terminal carboxylate groups were protonated.

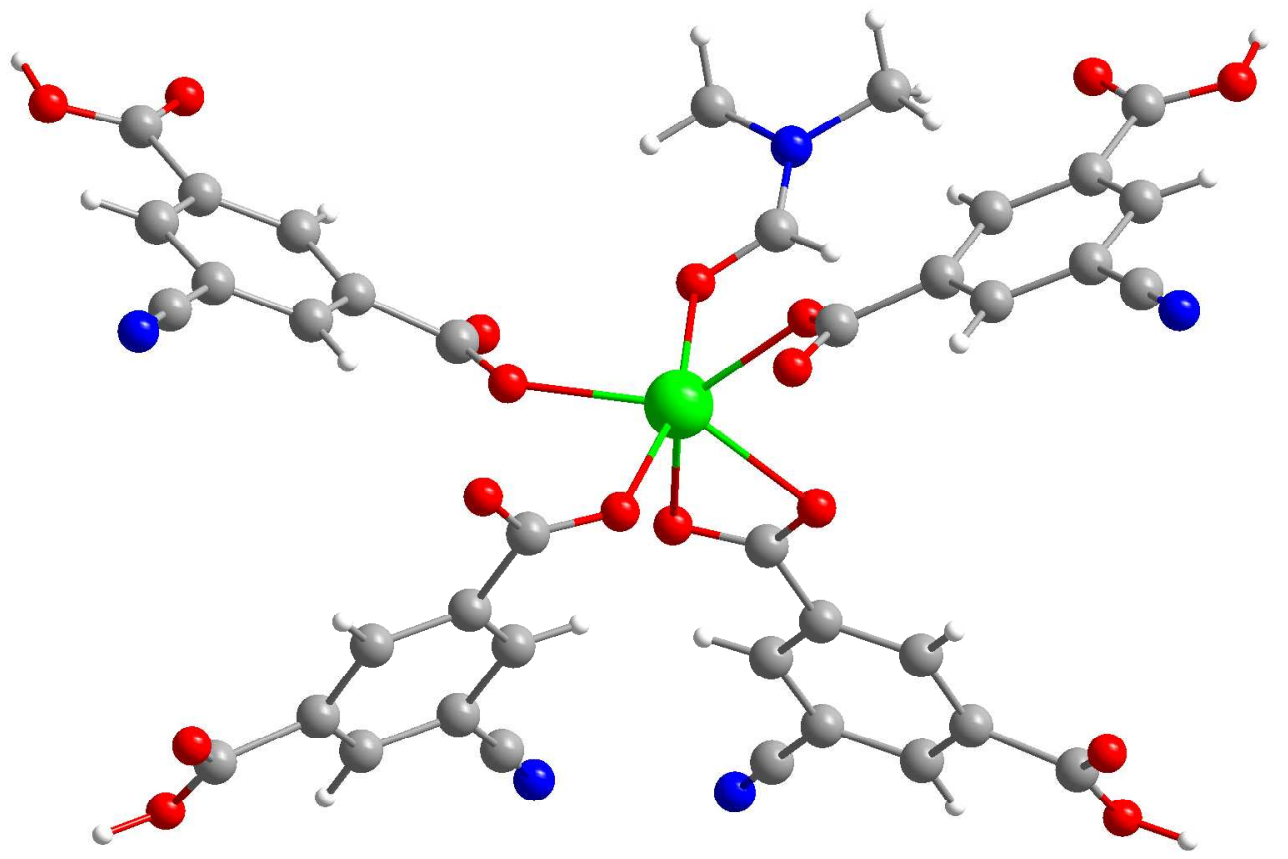

Figure S36. Molecular excerpt used as model 3 for the calculations.

Table S4. Calculated main emission energies $(\mathrm{nm})$ and electronic transitions of model $\mathbf{3}$ in gas phase.

\begin{tabular}{|c|c|c|c|}
\hline Calcd. $\lambda(\mathrm{nm})$ & Calcd. band $\lambda(\mathrm{nm})$ & Exp. $\lambda(\mathrm{nm})$ & Significant contributions \\
\hline 381 & 386 & 400 & $\begin{array}{l}\mathrm{HOMO}-4 \rightarrow \mathrm{LUMO}+3(91 \%) \\
\mathrm{HOMO}-5 \rightarrow \mathrm{LUMO}+3(4 \%)\end{array}$ \\
\hline 375 & 386 & 400 & $\mathrm{HOMO}-4 \rightarrow \mathrm{LUMO}+3(91 \%)$ \\
\hline 398 & 386 & 400 & $\begin{array}{l}\text { HOMO }-7 \rightarrow \text { LUMO }(54 \%) \\
\text { HOMO }-9 \rightarrow \text { LUMO }(32 \%) \\
\text { HOMO }-8 \rightarrow \text { LUMO }(12 \%)\end{array}$ \\
\hline 463 & 447 & 438 & $\begin{array}{l}\text { HOMO }-8 \rightarrow \text { LUMO }(59 \%) \\
\text { HOMO }-7 \rightarrow \text { LUMO }(33 \%)\end{array}$ \\
\hline 460 & 447 & 490 & $\begin{array}{l}\text { HOMO }-7 \rightarrow \text { LUMO }(44 \%) \\
\text { HOMO }-5 \rightarrow \text { LUMO }(33 \%) \\
\text { HOMO }-8 \rightarrow \text { LUMO }(15 \%)\end{array}$ \\
\hline $475-495$ & - & 490 & $\begin{array}{l}\mathrm{HOMO}-1 \rightarrow \mathrm{LUMO}+3(56 \%) \\
\mathrm{HOMO}-2 \rightarrow \mathrm{LUMO}+3(38 \%) \\
\mathrm{HOMO}-1 \rightarrow \mathrm{LUMO}+3(94 \%)\end{array}$ \\
\hline
\end{tabular}




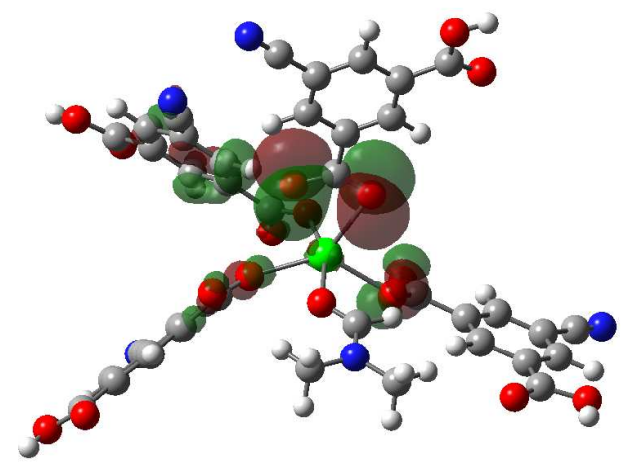

$\mathrm{HOMO}-9$

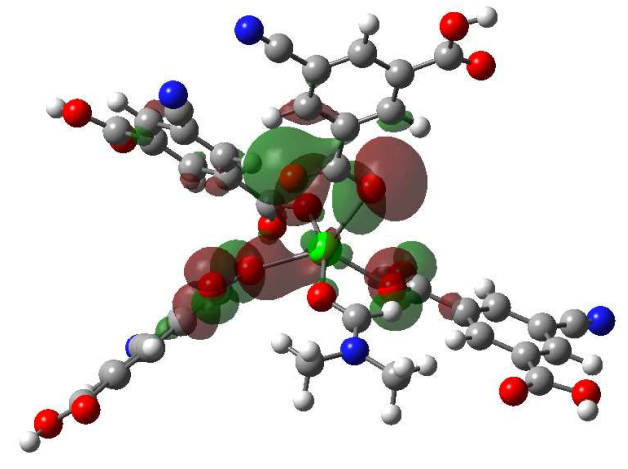

$\mathrm{HOMO}-7$

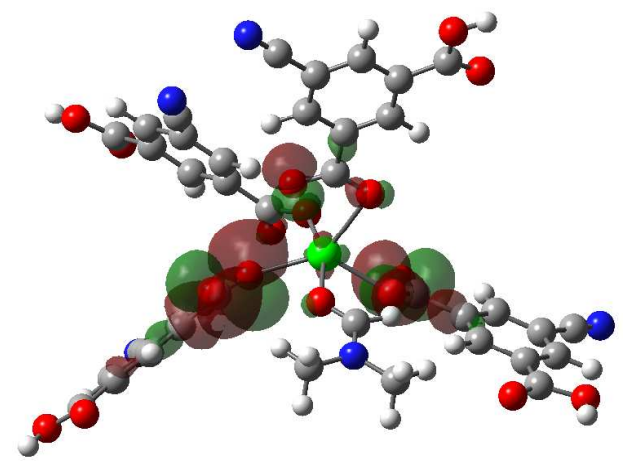

HOMO - 4

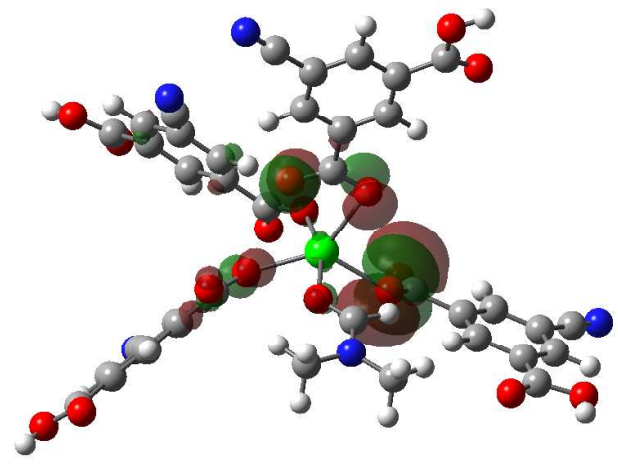

$\mathrm{HOMO}-8$

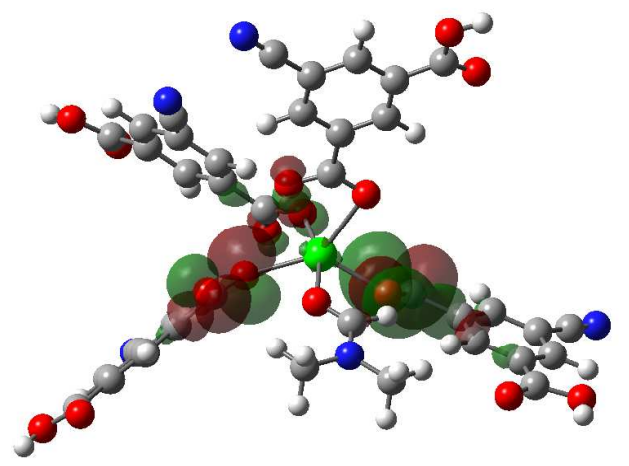

$\mathrm{HOMO}-5$

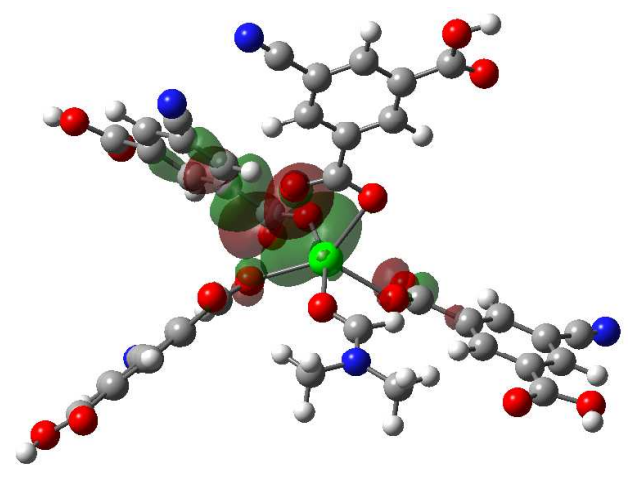

HOMO -2

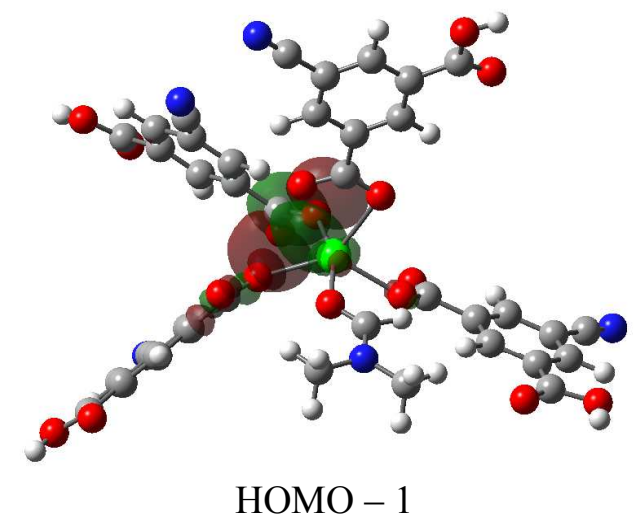

Figure S37. Highly Occupied Molecular Orbitals of excited state of model 3 involved in the main luminescent charge transitions. 


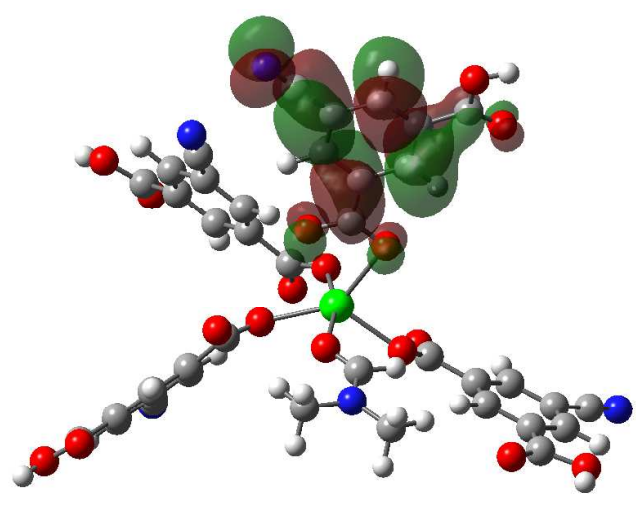

LUMO + 3

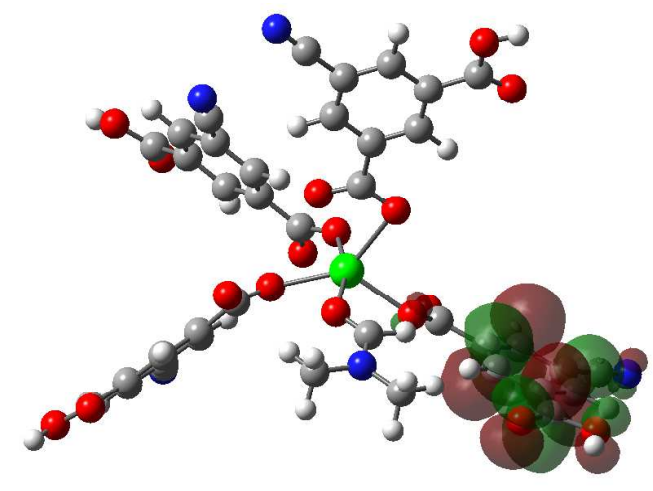

LUMO

Figure S38. Lowest Unoccupied Molecular Orbitals of ground state of model 3 involved in the main luminescent charge transitions. 